\title{
Las ondas largas de la política en el siglo $x x$
}

\author{
Gregorio Valdelvira González
}

\begin{abstract}
RESUMEN
ABSTRACT

En el siglo xx podemos distinguir dos grandes ciclos políticos de onda larga.

En el primero las dictaduras son fuertes y la democracia encuentra serias dificultades para mantenerse.

En el segundo los regímenes autoritarios son los débiles y la democracia se extiende y fortalece. Estos ciclos coinciden con otros de tipo económico. La concordancia se debe a que los problemas de cada

ciclo económico se abordan de manera más eficaz desde las correspondientes formas políticas generadas por los imperativos de la economía. Igual que las crisis de 1920 y 1929 contribuyeron a la expansión del fascismo y del autoritarismo, las de 1973 y 1979 coadyuvaron a la de la democracia. Este postulado no debe interpretarse de manera mecanicista;

se trata de explicar un proceso histórico general, el de las transiciones democráticas del último cuarto del siglo $x x$, investigando una de las claves, quizá la más importante, las fluctuaciones de la economía.

In the 20th century, we can differentiate two major long wave political cycles. In the first one, dictatorships become strong, while democracy finds itself at great pains to maintain its claims. In the second cycle, authoritarian regimes weaken and democracy spreads and grows stronger. There two cycles coincide with others of economic nature. This coincidence is due to the fact that in each economic cycle, problems are more efficiently dealt with as seen from their corresponding political systems, generated in turn by the imperatives of economy. In the same way as the crisis of 1920 and 1929 contribute to expand fascism and authoritarianism, so those of 1973 and 1979 also favoured the expansion of democracy. This postulate should not be interpreted in a mechanistic way; we are trying to explain a general historical process, the transitions to democracy in the final quarter of the 20th century, investigating one of the key factors, perhaps the fundamental one, which is the fluctuations in economy.
\end{abstract}


PALABRAS CLAVE

Autoritarismo, ciclos económicos, ciclos políticos, crisis económica, intervencionismo, keynesianismo, monetarismo, neoliberalismo, ondas

largas, transición democrática.
KEY WORDS

Authoritarian regimes, economic cycles, political cycles, economic crisis, interventionism, keynesianism, monetarism, neoliberalism, long waves, transition to democracy.

\section{INTRODUCCIÓN}

\subsection{Alternancia y naturaleza de los ciclos políticos}

La existencia de ciclos políticos de larga duración es posible observarla tanto en el siglo xx como en períodos históricos anteriores. Limitando el análisis al mundo contemporáneo, el siglo xIx es el del avance y expansión del sistema liberal parlamentario. En el último cuarto de la pasada centuria aparecen los primeros síntomas de crisis del liberalismo, que se agigantará hasta desembocar en dos largas décadas de predominio de los totalitarismos, durante el periodo de entreguerras. Las dictaduras aún constituirán sistemas fuertes y estables en los países con problemas económicos y sociales durante otros tres decenios más.

Sin embargo, a partir de la década de los setenta, se desmoronan las dictaduras del sur y del este de Europa, de América y del sur de África. Los regímenes autoritarios son los débiles y la democracia cobra prestigio y fortaleza, mientras que las alternativas revolucionarias también pierden vigencia.

Este nuevo hecho, la fortaleza de las democracias y la debilidad de las dictaduras, rompe con una situación de tantas décadas, que, sin duda, ha de deberse a cambios profundos de la realidad económica y social, a la aparición de nuevos fenómenos y a la necesidad de abordarlos de manera diferente.

Partimos, por tanto, de la hipótesis de que el flujo y reflujo de los sistemas políticos constituyen fenómenos de onda larga, que obedecen a transformaciones estructurales y cíclicas de la economía, a las que la sociedad se enfrenta adoptando las formas políticas más eficaces en cada ciclo histórico.

Los cambios de tendencia de régimen o gobierno están relacionados con los fines que se asignan a la política. $Y$ el fin último de ésta es el bienestar de la sociedad. Éste es el concepto de política desde Maquiavelo: símbolo de la voluntad colectiva, que tiende a la obtención del mayor bie- 
nestar posible ${ }^{1}$. En este mismo sentido, Mancur Olson destaca, entre los fines de la política, la satisfacción de los deseos de los individuos en el máximo grado posible en función de los recursos y del estado de la tecnología ${ }^{2}$. Pero, casi nunca una política concreta favorece a todos o lo hace en el mismo grado. Muy al contrario, siempre que se definen unas medidas, unos grupos ascienden en la escala económica, en su situación social y en su participación en el poder político, mientras que otros pierden posiciones. Vilfredo Pareto, al formular su concepto de optimalidad, señala que, puesto que no es posible mejorar la situación de todos los individuos y grupos sociales, la competencia entre estos por la reasignación de recursos lleva, en unos casos, a la elección de los sistemas de gobierno más adecuados para los intereses del grupo o grupos sociales más poderosos y, en otros, a la adopción de políticas que favorezcan al mayor número posible de individuos ${ }^{3}$. En consecuencia, cuando un sistema constituye un obstáculo para el desarrollo o se muestra incapaz de lograr mayor bienestar, aparecen alternativas de recambio.

Respecto a las interacciones entre factores económicos y sociales y la forma de organización política, la idea de que la economía, a diferencia de otros factores, "domina y dirige de hecho el obrar real de los hombres", tiene una larga tradición intelectual ${ }^{4}$.

E. Labrousse nos recuerda la conocida reflexión de Alexis de Tocqueville, afirmando que los fisiócratas habian ejercido más influencia que los filósofos en la revolución ${ }^{5}$. De la misma manera, otro eminente historiador, E. H. Carr, sostiene que «la experiencia demuestra que la estructura de la sociedad en cualquier tiempo y lugar, lo mismo que las ideas y creencias que sobre ella prevalecen, están en gran medida condicionadas por la forma como se satisfagan en dicha sociedad las necesidades materiales" 6 .

\footnotetext{
Véase la interpretación de Antonio Gramsci sobre la obra de Maquiavelo en La política y el Estado moderno, Barcelona, Península, 1971, antología de "ll materialismo storico e la filosofia di Benedetto Croce" y "Note sul Machiavelli, sulla politica e sullo stato moderno", publicada en Turín, Giulio Einandi Editore, 1949.

2 Mancur OLSON, "La relación entre las ciencias económicas y las otras ciencias sociales" en Seymour M. LIPSET (ed.), Política y ciencias sociales, Madrid, Guadiana, 1971, pp. 251-292.

3 Vilfredo PARETO, Forma y equilibrio sociales, Madrid, Alianza, 1980 y La transformación de la democracia, Madrid, Edersa, 1985.

4 Hermann Hellef, Teoría del Estado, México, Fondo de Cultura Económica, 1971, p. 231.

5 Ernest LABROUSSE, Fluctuaciones económicas e historia social, Madrid, Tecnos, 1973, p. 326. Alexis de TOCOUEVILLE desarrolla este pensamiento en el cap. III del libro $3^{\circ}$ de L'Ancien Régime et la Révolution (1.a ed. francesa de 1856). Véase en El Antiguo Régimen y la Revolución, Madrid, Guadarrama, 1969, pp. 207-208 y 214-215.

6 Edward Hallett CARR, La nueva sociedad, $4 .^{\circ} \mathrm{ed}$., Universidad de Puerto Rico, Editorial Universitaria, 1974, p. 33
} 
Las formas de gobierno sólo tienen consistencia si se corresponden con el sistema socioeconómico de un momento dado y posibilitan su desarrollo futuro. John Stuart Mill pone de relieve que «el mejor gobierno para un pueblo será el que tienda en mayor escala a facilitarle las condiciones sin las cuales no puede avanzar o avanzaría simplemente de una manera vacilante e incompleta»?

En relación con este entrelazamiento entre evolución económica y organización política, y siguiendo a Hondrich ${ }^{8}$, en los comienzos del capitalismo el mejor de los sistemas sería el liberalismo, que daba todas las ventajas a su inspirador, al capitalista, puesto que el contrato "libre" de trabajo, permitía el libre despido, mientras que la resolución del contrato por el trabajador lo conducía directamente al hambre. Al ascenso de la burguesía corresponde una concepción del mundo, que no es otra que el liberalismo «que, a fin de cuentas, no es más que la expresión de sus intereses económicos y políticos" ${ }^{9}$.

Aunque toda organización política responde a un determinado nivel de desarrollo económico y a los intereses de las clases dominantes, también hay que tener presentes los condicionamientos de orden político para el crecimiento económico. Éste encontrará facilidades allí donde el descontento político y la conflictividad social sean menores y la legitimidad y estabilidad política mayores. Si bien es cierto que las condiciones económicas crean nuevas realidades políticas, nuevos sistemas de relaciones sociales y nuevas concepciones intelectuales, no hemos de olvidar la fuerza de las ideas y el poder de la voluntad para transformar la realidad. Ale$x$ is de Tocqueville repudiaba «esos sistemas absolutos, que hacen depender todos los acontecimientos de la historia de las grandes causas primeras que se ligan las unas a las otras mediante una cadena fatal, y que eliminan a los hombres, por así decirlo, de la historia del género humano" ${ }^{10}$. Sobre la fuerza de las ideas y su influencia en la economía, en la sociedad y en todos los ámbitos de la vida humana, recordemos la reflexión de Keynes al final de su Teoría General: "Las ideas de los economistas y los filósofos políticos, tanto cuando son correctas como cuando están equivocadas, son más poderosas de lo que comúnmente se cree. En realidad el mundo está gobernado por poco más que esto. Los hom-

John Stuart Mill, Del gobierno representativo, Madrid, Tecnos, 1994, p. 27.

8 K. O. HONDRICH, Desarrollo económico, conflictos sociales y libertades políticas, Madrid, Euramérica, pp. 130-145.

9 Jacques Droz, Europa: Restauración y revolución, Madrid, Siglo veintiuno editores, 1974, p. 45.

10 Alexis de Tocouevil.Le, Recuerdos de la revolución de 1848, Madrid, Trotta, 1994, p. 80. 
bres prácticos, que se creen exentos por completo de cualquier influencia intelectual, son generalmente esclavos de algún economista difunto» ${ }^{11}$. En definitiva, actividades económicas, estructura social, formas politicas, desarrollo científico y cultural y voluntad humana se relacionan en interacción constante para alumbrar nuevas realidades históricas.

\subsection{Las interacciones entre ciclos económicos y ciclos políticos de onda larga}

El capitalismo se ha conducido desde sus orígenes de manera cíclica ${ }^{12}$. Históricamente, y con sorprendente regularidad, se repiten las crisis, los ciclos y sus fases: "La vida económica es en todos sus aspectos (precios, producción, cambios, ingresos, consumo) una sucesión de desequilibrios, una cadena de fluctuaciones de períodos más o menos largos, alternativamente de alza y baja, de contracción y expansión, de prosperidad y regresión, corrientemente clasificados según su duración» ${ }^{13}$.

Debemos a Schumpeter la distinción de tres tipos de ciclos básicos: El ciclo "corto" o "menor" de Kitchin (1923) con una duración de unos cuarenta meses. El ciclo “mayor» o "ciclo económico» de Juglar (1862), que dura unos diez años. Y el "ciclo largo" o ciclo Kondratieff (1926) de unos cincuenta años, veinticinco de alza y otros veinticinco de contracción ${ }^{14}$.

Respecto a la generalidad o tipicidad de los ciclos y crisis, se pueden distinguir dos posturas: la que sostiene que cada crisis es única y debe estudiarse por separado y la que defiende que, a pesar de las diferencias, es posible aplicar modelos, que permitan generalizar los fenómenos económicos cíclicos.

Es difícil que un solo modelo o teoría se pueda aplicar de manera general, pues la variedad de ciclos y crisis es amplia. Precisamente por esto, porque son distintas las circunstancias de cada crisis, sus causas, natura-

\footnotetext{
John Maynard KEYNES, Teoria general de la ocupación, el interés y el dinero, Barcelona Planeta-Agostini, 1993, p. 337 (1. ed ed. inglesa, 1936).

12 Véase en Charles P. Kind EBERGER, Manias, pánicos y cracs, Barcelona, Ariel, 1991, pp. 33 y ss

13 E. LABROUSSE, ob. cit., p. 340.

14 J. A. SCHUMPETER, Business Cycles: a theorical, historical and statistical analysis of the capitalist process, Philadelphia, Porcupine Press, 1964, cap. IV, pp. 105-162. Nicolai D. KonDRATIEFF publicó su trabajo sobre las ondas largas en alemán en t926; fue traducido al inglés en 1935: "The long Waves in Economic Life" en Review of Economic Statistics, nov. de 1935. En es pañol apareció bajo el título Las ondas largas de la economia, Madrid, Rev. de Occidente, 1946 La obra de Clément JugLAR, Les crises commerciales et leur retour périodique en France, en Angleterre et aux Etats Unis, data de 1862; después ha tenido muchas reediciones. Joseph Kitchin elaboró su teoría sobre el ciclo corto estudiando las compensaciones bancarias, la evolución de los precios y los tipos de interés, entre 1890 y 1922, en Gran Bretaña y EE. UU.
} 
leza, significación, desarrollo, duración, época, extensión, ramas económicas y grupos sociales a los que más afecta, es por lo que su solución exige respuestas económicas y políticas distintas. Un enfoque o teoría económica eficaz para dar solución a los problemas generados por una crisis concreta, puede resultar inservible para afrontar una crisis de causas, naturaleza y circunstancias distintas. $Y$ el contexto político para resolver más favorablemente esa crisis también habrá de ser diferente.

No obstante, todos los ciclos tienen en común que se desarrollan siguiendo unas mismas etapas. Es ya clásica la distinción de Schumpeter en cuatro fases: prosperidad, recesión, depresión y recuperación. El punto de inversión de la tendencia constituye la crisis ${ }^{15}$.

Las crisis "jalonan los grandes momentos de la historia económica (que) pueden ser también grandes momentos históricos", como las de $1789,1830,1847 . .$. , que provocaron revoluciones ${ }^{16}$; la de 1873 , que influyó en la aparición del gran capitalismo y del imperialismo; las de 1920 y 1929, que dieron lugar a ciclos políticos autoritarios y a políticas económicas intervencionistas; $y$ la de 1973 en la que enraiza un nuevo ciclo político y una política económica de orientación neoliberal.

En la salida de la crisis juegan un papel de primera magnitud las innovaciones empresariales $y$, sobre todo, el progreso técnico que abarata costes y ofrece nuevos productos. Esto es especialmente válido para los ciclos de onda larga, pues las innovaciones y puesta en marcha de nuevas empresas, técnicas y productos necesitan un tiempo para impulsar las inversiones y la producción. La prosperidad viene ligada a la introducción de una serie de cambios técnicos que exigen la fabricación de equipos modernos y la fundación de empresas. Según Niveau, "la aparición de las innovaciones en racimos es la responsable directa de los movimientos cíclicos» ${ }^{17}$. Aparecen juntas y en espacios breves de tiempo ${ }^{18}$. Los inventos de mayor alcance son los que explican los ciclos expansivos de onda larga o Kondratieff. El primero es el de la revolución industrial y el vapor; el segundo, el del ferrocarril y el acero; el tercero el de petróleo, la electricidad, la industria química y el automóvil.

15 J. A. SCHUMPETER, ob. cit., pp. 131-132 y Teoria del desenvolvimiento económico, México, F.C.E., 1976, en especial el cap. VI, “El ciclo económico”, pp. 213-254. Véase también Maurice NivEAU, Historia de los hechos económicos contemporáneos, 10. ed., Barcelona, Ariel, 1989, pp. 135 y 142.

16 E. LaBRousSe, ob. cit., p. 341.

17 M. Niveau, ob. cit., p. 135 y J.A. Schumpeter, Business Cycles, pp. 46 y ss., 63 y ss. y 122 y Teoría..., pp. 228 y ss.

18 Herman VAN DER WEE, Prosperidad y crisis. Reconstrucción, crecimiento y cambio, 1945 1980, vol. VI de Historia Económica Mundial del siglo xx, dirigida por Wolfram Fischer, Barcelona, Crítica, 1986, p. 262. 
Las épocas más innovadoras son las de depresión económica. Las principales innovaciones que originaron la primera revolución industrial son anteriores a 1789, año en que comienza la fase expansiva del primer ciclo Kondratieff. El ferrocarril pertenece a la fase depresiva de dicho primer ciclo. Durante la depresión que va de 1873 a 1896 hicieron su aparición los inventos que dieron lugar a la segunda revolución industrial y al gran capitalismo. En la depresión de 1929-47 la relación es igualmente extensa. Destaquemos, en los transportes, el rotor, la locomotora diesel, el avión a reacción, los cohetes; en electrónica, el transistor, la televisión, el microscopio electrónico, el radar; en la industria química, el polivinilo, el plexiglás, el DDT, el nilón y otras fibras sintéticas; en la industria farmacéutica, la penicilina, la estreptomicina; y así en otros muchos campos ${ }^{19}$.

Lo mismo ha ocurrido en el largo período de depresión que comienza en 1973 y que ha llegado hasta nuestros días. La relación de inventos e innovaciones es extensísima. Destacan el desarrollo de la informática y de la robótica. Los avances y su aplicación a los procesos productivos han sido espectaculares en física, astronomía, biología molecular y otras muchas ramas de la ciencia y de la producción.

Recapitulando, las innovaciones más importantes tienen lugar de forma conjunta durante las fases de depresión y su contribución al relanzamiento de la economía es decisiva. Además, estos inventos aparecen durante las fases depresivas de onda larga, generando prosperidad durante una fase de ciclo largo. Las transformaciones más sustanciales en la teoría económica y en los sistemas políticos ocurrirán también durante los períodos de recesión económica de ciclo largo.

Puesto que las transformaciones de los modelos económicos y de las formas políticas tienen lugar a continuación y como consecuencia de las crisis del ciclo de onda larga, examinaremos los cambios habidos en las fases depresivas subsiguientes a las crisis de los años veinte (1920 y 1929) y de los años setenta (1973 y 1979).

\subsection{Análisis comparativo de los ciclos del siglo $x x$}

La naturaleza del ciclo depresivo que comienza en la década de los veinte y, más aún, los sistemas teóricos elaborados para dar respuesta a la depresión y la política económica correspondiente explican el ciclo in-

19 Ibídem, pp. 262-263 
tervencionista en sus diversos aspectos. El intervencionismo, que favorecía el mantenimiento de regímenes autoritarios, se prolongaría, dado el éxito de las políticas aplicadas, hasta que otro ciclo de naturaleza distinta permitiera o exigiera otro tipo de respuestas con su correlato político diferente. Pero, las políticas económicas intervencionistas de ninguna manera determinaban regímenes políticos autoritarios como demuestran los países que conservaron un régimen constitucional, pues el capitalismo se gestiona mejor cuando los grupos sociales pueden manifestar y defender libremente sus opciones y se puede llegar a cierto equilibrio consensuado, aunque predominen los intereses de los más influyentes. No obstante, en los países donde el equilibrio y la armonía de intereses era difícil y la amenaza de ruptura constante, los grupos dominantes internacionales y nacionales recurrieron a las dictaduras.

En circunstancias distintas como las que concurrian en los años setenta, cuando los negocios demandaban más libertad económica y menor intervencionismo del Estado y el fomento de la economía se promovía mejor con un sistema de democracia formal, ésta encontraría escasos obstáculos para consolidarse. En esta situación, un control excesivo del Estado, tanto en el ámbito político como en el económico, genera rigideces, crea exclusividades y sustenta grupos de presión (empresariales o sindicales), que impiden el desarrollo de todas las fuerzas creadoras de riqueza.

Nos podemos preguntar por qué en las décadas de los años veinte y treinta progresaron las dictaduras, mientras que en las de los setenta y ochenta, decenios también de crisis, ha aumentado el número de países con regímenes democráticos. Para dar respuesta a estos interrogantes es preciso atender a dos cuestiones: en primer lugar, la naturaleza distinta de cada una de las crisis y, en segundo, el diferente contexto económico internacional.

Antes de la Segunda Guerra Mundial, las crisis generaban deflación y era necesario hacer frente al paro y reanimar el mercado con políticas intervencionistas que estimulasen el consumo interior. No importaba provocar déficits presupuestarios ni tomar medidas inflacionistas, pues el problema era la deflación.

Sin embargo, el gran problema de la economía desde 1973 es la estanflación, el estancamiento económico con inflación. Éste era un fenómeno nuevo, pues hasta entonces la depresión iba unida al estancamiento o caída de los precios. Atajar la inflación es el principal objetivo de la política económica. En caso contrario, la espiral precios-salarios conduce a una acelerada pérdida de competitividad, a la destrucción del tejido industrial y al aumento del paro. En este estado general de la economía, 
se considera que el intervencionismo agravaría la situación, pues la acción del Estado exige mucho dinero. Los impuestos excesivos gravan a empresas y particulares, de manera que los productos dejan de ser competitivos. Deuda pública e impuestos elevados detraen enormes cantidades de dinero de la inversión y asfixian la economía al elevar los costos.

En cuanto al contexto internacional, antes de la Segunda Guerra Mundial, los países desarrollados no tenían competidores y la recuperación se hacía sobre el mercado interior; en épocas de crisis se tendía al aislamiento y la autarquía, mientras que en la etapa actual, la recuperación se asienta sobre el mercado mundial. Para reducir costos y obtener mayores beneficios, los capitales acuden a algunos países en desarrollo, en los que se crean "zonas francas». En ellas las cargas fiscales y financieras son reducidas, los salarios muy bajos y la atención a las necesidades individuales y colectivas por parte del Estado, escasas. Esta situación ha sido justamente denominada "dumping social». Para hacer frente a esta competencia, también los países desarrollados tienen que rebajar costos y los gobiernos inician el desmontaje de la sociedad del bienestar.

La solución vendría del campo neoliberal. Los remedios keynesianos, que se basaban en el intervencionismo y en el avance de la sociedad del bienestar se mostraron ineficaces en la nueva coyuntura; no controlaban la inflación ni impulsaban el crecimiento económico. Sin embargo, el monetarismo propugnaba una serie de medidas para contener la inflación y ganar competitividad, en especial la regulación y limitación de la masa monetaria, el desligamiento del Estado de las actividades económicas y sociales y el restablecimiento del libre mercado.

Realmente, esta política no contribuye a redistribuir la riqueza; más bien beneficia a los poderosos y priva de protección a los más desfavorecidos, debido al recorte o supresión de prestaciones sociales. Sin embargo, el aumento de las desigualdades y la pérdida de cuota de participación de los salarios en la renta nacional no moviliza a la sociedad por el temor de los trabajadores a que peligren las inversiones y los puestos de trabajo. Los sindicatos pierden capacidad de convocatoria y movilización. La conflictividad social desciende.

Las dictaduras encuentran muchos más problemas que las democracias para aplicar esta política, que en muchos casos es fruto del consenso. Bajo un régimen democrático se llega con cierta facilidad al entendimiento entre sectores políticos y sociales. Sin embargo, la negociación no es posible bajo un régimen dictatorial, que no reconoce sindicatos ni partidos. Las dictaduras no se encuentran en condiciones de reconvertir la economía, arrojar al paro a numerosos obreros y atacar la sociedad del bienes- 
tar: estas medidas provocarian una enorme conflictividad social que acabaría arruinando la economía. Por ello, en casi todos los casos, los regímenes autoritarios cayeron mediante transición pacífica, salvaguardando la paz social. Ésta era la salida con menos costos sociales, económicos y políticos para la población en general y también la más beneficiosa para los grupos dominantes nacionales e internacionales.

\section{LOS CICLOS POLÍTICOS DE ONDA LARGA EN EL SIGLO XX}

II.1. Primer ciclo: Las políticas keynesianas, el intervencionismo estatal $y$ el auge de los autoritarismos

II.1.1. Las crisis de los años veinte. Las interpretaciones monetarista y keynesiana de la crisis de 1929

El desarrollo de las crisis de 1920 y 1929 es muy conocido. También las teorías y las políticas económicas a que dieron lugar han sido muy estudiadas. Aquí sólo interesan en tanto sirvan para esclarecer y apoyar las hipótesis expuestas en los párrafos anteriores. No se trata por tanto de describir pormenorizadamente la evolución de la economía ni las doctrinas económicas ni la instauración y expansión de las dictaduras, sino de explicar sus claves.

La crisis de 1920 fue una crisis de reconversión. Tras la firma del armisticio, a lo largo de 1919 y parte de 1920, creció la inversión y la industria absorbió a los soldados desmovilizados, alejándose los temores de paro. La demanda de bienes generó una fuerte inflación. Estados Unidos y Gran Bretaña decidieron atajarla con políticas monetarias restrictivas: el resultado fue la crisis de 1920. Como Alemania y Europa central continuaron creando abundante dinero, la crisis se retrasó, y la inflación se convirtió en hiperinflación ${ }^{20}$.

Al quedar interrumpida la reconstrucción y truncarse la transición fácil a las condiciones de paz, innumerables fábricas cerraron, los parados se contaron por millones y los salarios descendieron a niveles muy bajos. $\mathrm{La}$ conflictividad social creció hasta tal punto, que en algunos paises hubo levantamientos revolucionarios de carácter socialista.

20 Derek H. Aldcroft, De Versalles a Wall Street, 1919-1929, Barcelona, Crítica, 1985 , pp. $46-48$. 
En este ambiente de crisis, donde los problemas se manifestaron con más crudeza, generando un clima de inseguridad e inestabilidad, las clases dominantes amenazadas ya no encontraron otro recurso que la dictadura y el fascismo.

Pero lo que aquí interesa es resaltar cómo el ciclo económico creaba las circunstancias propicias para la instauración de regímenes autoritarios. Cuando los remedios utilizados por las democracias no surtieron efecto, las monedas no se estabilizaron, la economía no despegaba, la deuda no hacía más que crecer, el paro se disparaba tanto en la industria como en el campo, la crisis arruinaba a las clases medias y la conflictividad creaba un peligroso pesimismo social, amplias capas sociales no vieron otro remedio que el intervencionismo económico, que, en esas circunstancias, exigía un ejecutivo más fuerte.

La relación entre intervencionismo económico y autoritarismo ha sido puesta de manifiesto por F.A. Hayek: "La mayoría de los planificadores que han considerado en serio los aspectos prácticos de su tarea apenas dudan que una economía dirigida tiene que marchar por líneas más o menos dictatoriales" 21.

Donde se establecieron dictaduras, el gobierno no tuvo cortapisas para apoyar a las empresas, crear monopolios, subvencionar la agricultura, realizar grandes obras públicas y planificar la economía. Las transformaciones políticas de este periodo «deben considerarse al mismo tiempo como factores y como efectos de la crisis" ${ }^{22}$.

El ultranacionalismo y el fascismo ascendieron en Italia como consecuencia de la crisis económica, del aumento de la conflictividad, de la fortaleza de los partidos de izquierda y de la falta de autoridad del gobierno y su incapacidad para tomar medidas eficaces para hacer crecer la economía y satisfacer las demandas sociales. Mussolini representaba orden, paz social, seguridad y capacidad para enderezar la situación económica y aplicar remedios eficaces. Ésta es la razón principal de su éxito: la opinión pública, ante el desastre económico y tanto fracaso para solucionarlo, llegó al convencimiento de que «un régimen autoritario estaría en mejores condiciones para indicar e imponer los medios de recuperación" que un régimen parlamentario, que era incapaz de hallar soluciones "ni siquiera por el procedimiento de los decretos-leyes» ${ }^{23}$.

\footnotetext{
Friedrich A. HAYEK, Camino de servidumbre, Madrid, Alianza, 1985, p. 121

22 P. Delfaud, et. al., Nueva historia económica mundial (siglos $x I X-X X)$ ), Vicens-Vives, 1984, pp. 498-99.

23 Pierre Renouvin, Historia de las relaciones internacionales, t. II, vol. II, Madrid, Aguilar, 1969, p. 954.
} 
Bastó la "Marcha sobre Roma" para que las máximas instituciones, desesperanzadas y frustradas por la evolución del país, entregaran el poder a Mussolini.

El triunfo del fascismo en Italia provocó la aparición en otros países de partidos que se inspiraban en aquél, aunque, en general, en la década de los veinte, donde triunfó el autoritarismo lo hizo bajo las formas de nacionalismo autoritario o dictadura tradicional: España, Portugal, Polonia, Lituania, Yugoslavia, Hungría ${ }^{24}$. En todos estos países el Estado intervino otorgando monopolios a empresas privadas, tales como teléfonos o petróleo, subvencionando a la agricultura y la industria, incrementando las tierras de regadío, realizando obras públicas (carreteras, ferrocarriles, obras hidráulicas), proyectando mejoras urbanísticas y creando empresas estatales.

En 1929 se sumaron una crisis de ciclo largo y otra de ciclo medio. Esta crisis fue más aguda, más prolongada y más universal que todas las anteriores. Es una crisis singular en muchos aspectos: sobreviene en una economía ya estancada con parte del utillaje infrautilizado, materias primas abundantes y altos índices de paro; por lo demás, el crack bursátil llegó cuando ya hacia tiempo que la actividad económica estaba descendiendo.

Las interpretaciones son numerosas. Cada escuela concede mayor peso a algunos de los elementos desencadenantes. Las explicaciones que más nos interesan son la de Keynes, porque de ella se derivó la teoría que fue aplicada con éxito para salir de la crisis y para mantener la prosperidad durante varias décadas, y la monetarista, de la que emanarán los postulados neoliberales para remediar las crisis de los años setenta y ochenta.

Según los monetaristas, el origen de la crisis se encuentra en la política monetaria de los Estados Unidos. En 1927, la máxima autoridad monetaria, el Sistema de Reserva Federal, quiso evitar el hundimiento de la economía aumentando la cantidad de dinero y ampliando el crédito. El «boom» que siguió a estas medidas estuvo acompañado de una fortísima inflación. Para frenar la especulación bursátil y la inflación, en 1928 y 1929, la Reserva Federal adoptó una política crediticia restrictiva. Entre 1929 y 1933 la Reserva Federal cometió un error de consecuencias desastrosas: redujo en un tercio la cantidad de dinero, «lo que convirtió una recesión severa en una depresión catastrófica» ${ }^{25}$; y más cuando las medidas restrictivas se prolongaron en el tiempo. Cuando faltó liquidez se re-

\footnotetext{
24 Stanley G. PAYNE, El fascismo, Madrid, Alianza, 1982, pp. 112-13 y A. FeanÁndez Garcia y J. L. Rodriguez Jiménez, Fascismo y neofascismo, Madrid, Arco, 1996, p. 33.

${ }_{25}$ Milton Friedman, Paradojas del dinero, Barcelona, Grijalbo, 1992, p. 248.
} 
tiraron los fondos colocados en Europa central y oriental. El sistema monetario y financiero de estos países, especialmente de Alemania y Austria, se derrumbó.

De acuerdo con Hayek, la depresión habría durado tanto, unos quince años, cuando sólo se debía haber prolongado durante dos o tres años, debido al intento de superarla con la política de salarios altos iniciada por Hoover y continuada por Roosevelt ${ }^{26}$.

La explicación de Keynes se encuentra en el polo opuesto. M. Friedman la expone de la siguiente manera: La ecuación de Irvin Fisher, teórico cuantitativista, establece que MV = PT, el dinero multiplicado por la velocidad de circulación es igual a los precios multiplicados por el volumen de las transacciones. Keynes aun aceptando la validez de la ecuación, dijo que la velocidad era muy adaptable y, por consiguiente, nada estable: si aumenta la cantidad de dinero, disminuirá la velocidad de circulación y no afectará a los precios ni a la producción; si algo afecta a los precios o a los ingresos, disminuirá la velocidad. Por tanto, la cantidad de dinero no afecta a los precios, que son muy rígidos, mientras que las cantidades de dinero cambian con facilidad. Lo importante es la parte del gasto total que es independiente de los ingresos corrientes, el gasto autónomo, que se identifica con las inversiones de las empresas y del Estado. El colapso de éstas fue la causa de la depresión. Para activarla habría que rebajar los costos, sobre todo del dinero, bajando los tipos de interés. Para Keynes, en efecto, la gran recesión fue resultado de un colapso de la demanda de inversión, lo que a su vez se debió a un colapso de las oportunidades productivas para invertir ${ }^{27}$.

\section{I.1.2. Principales tesis del keynesianismo}

La teoría de Keynes está expresada en su Teoría General. En esta obra pretende dar respuesta a los dramáticos problemas económicos y sociales de su tiempo. El resumen de las implicaciones sociales y políticas, las que a nosotros más nos interesan, de su doctrina económica se encuentra en las «notas finales" que constituyen el capítulo veinticuatro, que aquí seguimos ${ }^{28}$. Las proposiciones más importantes de Keynes son las siguientes:

26 F. A. HAYEK, ob. cit., pp. 249-50 y A. GÉLÉdAN (dir.), Les mutations de l'économie mondiale (1975-1991), Paris, Le Monde Éditions, 1990, p. 196.

27 M. Friedman, La economía monetarista, Barcelona, Gedisa, 1992, pp. 13-19.

28 J. M. KEYNES, Teoría General..., pp. 328-337. 
1. ${ }^{\text {a }}$ La cuestión fundamental es la incapacidad del sistema para procurar ocupación plena y distribuir más justamente la riqueza. El método seguido, desde el siglo XIX, para aminorar las enormes desigualdades sociales había sido la imposición directa sobre los ingresos y sobre la herencia. Varias razones habían impedido llegar más lejos por este camino: el temor a la evasión de capitales y a la disminución de incentivos para correr riesgos y, sobre todo, por la creencia de que el crecimiento dependía del ahorro individual, sobre todo del de los ricos. Keynes piensa que esta última creencia es errónea. Asegura que el gasto corriente en consumo es muy estable y que depende de la renta corriente: cuando la renta aumenta, el consumo no lo hace en "una suma absoluta igual»; a medida que aumenta la renta, se ahorra una mayor proporción de la misma, que no se emplea en consumo ${ }^{29}$. Sobre la, según Keynes, absurda idea de que el ahorro es tan bueno como la demanda efectiva, escribe en otro capítulo del libro: "Un acto de ahorro individual significa, por decirlo así, el propósito de no comer hoy; pero no supone la necesidad de tomar una decisión de comer o comprar un par de botas dentro de una semana o de un año o de consumir cualquier cosa concreta en fecha alguna determinada. De esta manera deprime los negocios de la preparación de la comida de hoy sin estimular los que preparan algún acto futuro de consumo. No es una sustitución de la demanda de consumo presente por demanda de consumo futuro, sino una disminución neta de la primera» ${ }^{30}$.

En realidad, la producción crece con la redistribución de los ingresos, factor que eleva la propensión a consumir, y no con el aumento de la capacidad de ahorro de los ricos. El nivel de producción depende de la capacidad de consumo del conjunto de la población. Esto se puede lograr elevando los salarios para aumentar el poder adquisitivo. Para los clásicos, la recuperación suponía que bajasen los costos, entre ellos los salariales, pero para Keynes era necesario invertir los términos. Un descenso de los salarios haría descender los precios en la misma proporción, pero también disminuiria la propensión a consumir y, por tanto, la producción caería por ambos conceptos. En consecuencia, la disminución de los salarios, contra lo que pudiera creerse, aumentaba el desempleo.

El déficit presupuestario tendría el mismo efecto expansivo sobre la economia, ya fuera financiado tomando dinero del público o imprimiendo

29 Véase también M. Friedman, Una teoria de la función de consumo, Madrid, Alianza, 1973 , p. 17.

30 J. M. KEYNES, ob. cit., p. 188. 
dinero, pues los precios no dependen de la cantidad de dinero, sino de los costos. Para salir de la crisis, el gobierno debía pedir dinero prestado y gastarlo ${ }^{31}$.

Estaba extendida la idea de que el impuesto sobre la herencia reducía la acumulación de capital y por tanto la capacidad de inversión. Sin embargo, este impuesto, en opinión de Keynes, hace posible que disminuyan los impuestos sobre los ingresos y el consumo, de modo que aumenta la propensión a consumir de la comunidad y con ella el aliciente para invertir.

Con estas formulaciones quedaban desmontadas las principales justificaciones para mantener grandes desigualdades de riqueza. A pesar de todo ello, Keynes cree que existen razones de tipo social y psicológico para mantener ciertas desigualdades en los ingresos y en la riqueza, aunque tendiendo a una mejor redistribución. Hay actividades cuyo desarrollo exige estímulo para enriquecerse y las condiciones que crea la propiedad privada.

2. Conveniencia de reducir la tasa de interés hasta lograr ocupación plena, sin intentar reducirla más a partir de ese momento. Es cierto que una tasa de interés moderadamente alta incita al ahorro. Pero el ahorro efectivo está determinado por la inversión y ésta se fomenta con una tasa de interés baja. Para alentar los tipos de interés bajos es necesario aumentar la cantidad de dinero; de esta manera, aunque se mantendría cierto grado de individualismo, llegaría la "eutanasia del rentista» y la del "poder de opresión acumulativo del capitalista para explotar el valor de escasez del capital» ${ }^{32}$.

3. ${ }^{\text {a }}$ Estos planteamientos obligan a reforzar y extender los controles y la intervención del Estado a campos que estaban por completo en manos de la iniciativa individual. El Estado tendria que orientar la propensión al consumo a través de los impuestos, la tasa de interés y otros medios. Keynes plantea una "socialización bastante completa de las inversiones" 33 como único medio para aproximarse a la ocupación plena, aunque manteniendo la cooperación con la iniciativa privada.

Uno de los medios para elevar el poder adquisitivo es aumentar los gastos del Estado, mediante grandes obras y otras intervenciones, recurriendo para ello, si es preciso, al déficit presupuestario. La teoría clásica

\footnotetext{
31 Véanse M. Friedman, La economia monetarista, pp. 18-19 y 24 y J. K. Galbraith, La era de la incertidumbre, Barcelona, Plaza y Janés, 1984, pp. 210-11.

32 J. M. KEYNES, ob. cit., p. 331.

33 Ibídem, pp. 332-33.
} 
afirmaba que los mecanismos económicos tienden a un equilibrio de la producción y del consumo que asegura el pleno empleo. Keynes demuestra que la economía no se comporta de esta manera, que era necesaria la intervención del Estado.

En todo caso, «no es la propiedad de los medios de producción la que conviene al Estado asumir" ${ }^{34}$. Al Estado le compete sólo determinar la cantidad de recursos destinados a aumentar los medios de producción y la tasa de remuneración de quienes los poseen.

Keynes critica la teoría económica clásica por su incapacidad para resolver los dos problemas que hemos comprobado que más le preocupan, el pleno empleo y la distribución de la riqueza. Logrado esto, desea conciliar la teoría clásica con las nuevas necesidades sociales y políticas. Si el control central logra establecer el volumen de producción necesario para alcanzar el pleno empleo y consigue el ajuste entre la propensión a consumir y el aliciente para invertir, en el resto dominará el interés personal, que determinará lo que se producirá, en qué proporciones y cómo se distribuirá. $Y$ ello porque el individualismo también tiene enormes ventajas: eficacia de las descentralización de las decisiones, de la responsabilidad personal, del juego del interés individual y, por encima de todas, salvaguardar la libertad personal y de elección. No obstante, la ampliación de las funciones del gobierno es "el único medio practicable de evitar la destrucción total de las formas económicas existentes» ${ }^{35}$.

\section{II.1.3. La crisis del liberalismo. Fascismos y democracias en el periodo de entreguerras}

La crisis de 1929 tuvo consecuencias económicas y políticas de enorme magnitud. El dirigismo de la economía provocó la crisis de las instituciones liberales; la necesidad de tomar decisiones con rapidez y contundencia tropezaba con el, a veces, lento trámite parlamentario, de manera que el ejecutivo fue acumulando poderes a costa del legislativo.

En algunos países las dificultades políticas que entrañaba la crisis económica condujeron a la dictadura y el fascismo. Los graves problemas a los que se enfrentaba la población hicieron prevalecer el deseo de seguridad sobre el de libertad. Ello se debió a que en los países en los que la crisis fue más grave y profunda se extendió la idea de que un régimen

34 Ibídem, p. 333.

35 Ibídem, p. 335. 
fuerte e intervencionista era capaz de manejar mejor la situación de una economía en crisis que un régimen liberal. También se debía a que la única doctrina económica que supo resolver los problemas de la crisis, la de Keynes, era intervencionista. Esto no quiere decir que todos los gobiernos aplicaran conscientemente los principios de la Teoría General. Pero, ante problemas similares, surgen, en muchos sitios a la vez, soluciones parecidas. $Y$, de una manera $u$ otra, las ideas keynesianas fueron impregnando la atmósfera intelectual y el campo de la teoría económica y penetrando en los centros de decisión política, convirtiéndose en la mejor vía para relanzar la economía.

No es preciso recordar que Keynes no propugnaba ningún tipo de autoritarismo. Remarquemos que era un convencido demócrata, que quería preservar la democracia y el capitalismo por la vía de una mejor distribución de la riqueza, salvaguardando el interés y la libertad personales para producir y consumir y manteniendo la propiedad privada de los medios de producción. Sin embargo, el único medio para atajar la crisis y mantener un crecimiento económico sostenido era "ampliar las funciones del gobierno", "reforzar y extender los controles del Estado" a áreas económicas que estaban en manos privadas y que los poderes e instituciones públicas orientasen el consumo, dirigiesen y determinasen los recursos y las inversiones, estableciesen el volumen de producción y creasen empresas.

La puesta en marcha de esas fórmulas encontraba grandes dificultades en los países con régimen parlamentario, como en los Estados Unidos, donde muchas de las medidas de Roosevelt encontraron enormes obstáculos para aplicarse y algunas, como la "Agricultura Adjustement Act", fueron invalidadas por el Tribunal Supremo. La potencialidad económica de éste y algún otro país pudo superar esas dificultades, pero en países con economía más débil el margen de maniobra era pequeño y las medidas se tenían que aplicar con decisión y sin cortapisas. $Y$ el sistema que más esfuerzos ahorraba era el autoritario.

El caso alemán ilustra perfectamente estos planteamientos. Charles Bettelheim estudió, hace ya muchos años, las raíces económicas del nazismo alemán y la dinámica económica que engendró su desarrollo ${ }^{36}$. Para que la economía alemana, que, a la altura de 1932-33, había tocado fondo, despegase era necesario reactivar la demanda interior y obtener mercados en el exterior. El mercado interior era difícil que creciese debido

36 Charles Bettelheim, La economía alemana bajo el nacismo, Madrid, Ed. Fundamentos, 1972. 
al aumento del paro y a la caída de los precios agrícolas. Por otro lado, era muy difícil abrir mercados en el exterior a causa de las tendencias autárquicas y proteccionistas y del desorden monetario internacional. La demanda sólo podía aumentar a base de los pedidos del Estado, pero para ello tenía que endeudarse o aumentar los impuestos. Bettelheim señala la existencia de cuatro posibles caminos para salir de la crisis: $1^{\circ}$ La revolución socialista. Con una nueva redistribución de la riqueza sería posible ampliar el mercado interior. Pero ya el movimiento espartaquista había demostrado su incapacidad para hacerse con el poder. $2^{\circ}$ La devaluación monetaria. El recuerdo y la impopularidad de la no tan lejana hiperinflación. $3^{0}$ Ayuda financiera exterior. Se corría el peligro, intolerable para Alemania, de caer en una especie de colonialismo financiero.Quedaba la solución nacional-socialista: incentivar el mercado interior con pedidos del Estado mediante obras públicas y rearme militar. Después, el ejército abriría mercados en el exterior ocupando territorios. Ésta es de hecho la vía que se adoptó, aunque "en ninguna parte está escrito que el nazismo fuera la única solución a las dificultades alemanas" ${ }^{37}$. No obstante, el nazismo "encontró una primera base política en la propia crisis económica" ${ }^{38}$.

El fascismo italiano intensificó el intervencionismo económico a partir de 1929 para hacer frente a la crisis. El Estado emprendió obras públicas e invirtió en numerosos sectores de la economía. En 1933 se creó el Instituto para la Reconstrucción Industrial (IRI), que llegó a poseer el 17\% de la industria italiana. El control estatal se hizo aún más patente en la política de armamento con el fin de lograr la autarquía en el terreno bélico.

En Japón la caída de las exportaciones repercutió en la industria debido a la carencia de divisas para comprar materias primas y productos energéticos. Los grupos empresariales empezaron a inclinarse hacia la expansión territorial, única manera de obtener esas materias, ampliar mercados y superar la crisis. Esta expansión formaba parte consustancial de la ideología de los grupos fascistas. Y el ejército, que encarnaba la política nacionalista y expansionista sería el encargado de llevarla a cabo. Para esta misión era imprescindible un Estado fuerte, que controlase a los sectores opuestos a la oligarquía y a la política expansionista, mediante la censura, la restricción de las libertades y la exaltación nacionalista y, sobre todo, para elaborar y llevar a cabo un plan económico y de expansión territorial con fines económicos: obtención de materias primas y conquista de mercados para colocar mercancías y capitales.

37 P. Delfaud, et al., ob. cit., p. 498.

38 Ch. Bettel.heim, ob. cit., p. 41. 
Los golpes de Estado, las dictaduras y el ascenso al poder de partidos fascistas se multiplicaron en Europa. Los sistemas democráticos se hundieron a consecuencia de la crisis y la depresión. La conflictividad en el campo era dificil de contener y en las zonas industriales proliferaron las huelgas y los conflictos. El temor de las clases reaccionarias y de los gobiernos condujo al autoritarismo.

En España, la II República fue derribada tras una trágica y cruenta guerra (1936-39). El conflicto terminó con el triunfo nacionalista, iniciándose a continuación la dictadura franquista, que se extendería a lo largo de cuatro décadas. Cuando la República emprendió un programa de reformas de izquierdas, las clases dominantes, al comprobar que su situación privilegiada se encontraba en peligro, empezaron a organizar la ofensiva contra la República y más adelante el alzamiento militar. El triunfo del Frente Popular en 1936, según lo interpretaba Largo Caballero, debía concretarse, en el plano práctico, en la constitución de un frente obrero que impusiese su hegemonía no sólo sobre la oligarquía sino también sobre la burguesía progresista, incluida aquélla que habia integrado el Frente Popular. Con el triunfo franquista, España se sumaba a la larga lista de dictaduras europeas.

La situación económica y política internacional y la crisis económica y social interna favorecieron la aparición o el fortalecimiento de las dictaduras en América Latina. Los intentos de reforma social y de instauración de regímenes democráticos fracasaron en casi todas las ocasiones y terminaron con el advenimiento de dictaduras para contrarrestar esos movimientos. Así ocurrió en Uruguay, Argentina, Ecuador o Chile, durante las primeras décadas del siglo. Los movimientos revolucionarios fracasaron en Brasil (1927), El Salvador (1932) y Chile (1932). En los años treinta, tanto en algunos de los países citados (en Argentina en 1930, en Uruguay en 1933, en Ecuador en 1937), como en Guatemala, Cuba, Honduras, Nicaragua, Paraguay, Perú, República Dominicana, Venezuela, Bolivia, etc., continuaron o triunfaron regímenes caudillistas y oligárquicos ${ }^{39}$.

El mejor ejemplo de los éxitos de un Estado totalitario era la Unión Soviética. Destruida por la Guerra Mundial y la posterior guerra civil, en sólo diez años de planificación se había convertido en la tercera potencia económica mundial.

El cada vez más reducido número de países que conservaron las instituciones democráticas (Estados Unidos, Gran Bretaña y sus dependen-

39 Véase Marcos RoItMan Rosenmann, "Espacios y tiempos de la democracia en América Latina" en Política y Sociedad, n¹7, sept.-dic. de 1994, pp. 23-40. 
cias, Francia, Bélgica, Países Bajos, Suiza, Checoslovaquia y los países escandinavos) se vieron obligados a abandonar el puro "sistema de Manchester" y ensanchar las funciones del gobierno, como aconsejaba Keynes, aunque, como también defendiera este genial economista, conservando un "amplio campo para el ejercicio de la iniciativa y la responsabilidad privadas", pues "por encima de todo, el individualismo es la mejor salvaguarda de la libertad personal si puede ser purgado de sus defectos y abusos, en el sentido de que, comparado con cualquier otro sistema, amplía considerablemente el campo en que puede manifestarse la facultad de elección personal. También es la mejor protección de la vida variada, que brota precisamente de este extendido campo de la facultad de elección, cuya pérdida es la mayor de las desgracias del estado homogéneo o totalitario" ${ }^{40}$.

En los años treinta la democracia liberal «duda de sí misma». Se dice que es el mejor sistema en épocas de prosperidad, pero se duda acerca de su capacidad para sacar a los países de la crisis ${ }^{41}$. La práctica de la economía dirigida favorecía una tendencia, que desde hacía diez años hacía "batirse en retirada a las instituciones liberales y parlamentarias» ${ }^{42}$. Implicaba que el Estado poseía medios para tomar con rapidez las medidas necesarias y subordinar los intereses particulares al interés nacional.

Los cambios políticos fueron importantes. El ejecutivo amplió sus atribuciones en detrimento del legislativo en aras de la eficacia. En Estados Unidos el presidente aumentó sus poderes y el gobierno federal asumió funciones que antes eran de los estados ${ }^{43}$. Roosevelt intervino activamente en la economía. El «New Deal» constituyó un buen ejemplo de aplicación de las teorías de Keynes. Los resultados fueron desiguales, pero lo que conviene subrayar es que el «New Deal» supuso una auténtica revolución al introducir el dirigismo estatal en la política económica y dar los primeros pasos hacia la planificación económica, el neocapitalismo y el Estado del bienestar.

En Gran Bretaña y Francia muchos de los poderes del legislativo fueron transferidos desde el Parlamento a departamentos del ejecutivo. En todos los países aumentó la intervención del Estado, que asumió la dirección de la economía para ayudar a las empresas y crear empleo. Se llegó a la nacionalización y a la creación de un poderoso sector público. El Estado

40 J. M. KEYNES, ob. cit., p. 334.

4 P. Delfaud, et al., ob. cit., p. 499.

42 P. Renouvin, ob. cit., p. 954.

43 Maurice CRouzet, La época contemporánea, $4 .^{a}$ ed.,vol. VII de Historia General de las civilizaciones, Barcelona, Destino, 1973, p. 198. 
asumió la iniciativa en los sectores en los que no invertía la empresa privada, emprendió grandes obras públicas e incrementó su participación en la industria de armamentos; impuso un severo proteccionismo aduanero, llegando en ocasiones a monopolizar el comercio exterior. Los servicios públicos también pasaron a depender del Estado, que extendió, al mismo tiempo, las medidas de seguridad social y, en definitiva, inició el camino hacia la sociedad del bienestar.

\section{II.1.4. Pervivencia del keynesianismo tras la Segunda Guerra Mundial. El Estado del bienestar}

Las teorías de Keynes siguieron vigentes después de la Segunda Guerra Mundial, en la que los gobiernos intervinieron, más que en ninguna otra época anterior, todos los ámbitos de la actividad humana. La política económica, inspirada en economistas keynesianos como Galbraith, consistió, básicamente, en la intervención del gobierno para dominar la inflación mediante una fuerte política fiscal, una alta tasa de interés y una fuerte restricción presupuestaria, siempre que se recalentaba la economía; por el contrario, cuando el desempleo se convertía en una amenaza, sus efectos negativos se contrarrestaban con medidas opuestas a las de la fase de expansión: reducción de la tasa de interés, elevado gasto público, etc. ${ }^{44}$.

Frente a los ataques a los sindicatos y a su papel en la sociedad actual, Galbraith introduce la noción de "poder compensador", de equilibrio, función que representan los sindicatos y las organizaciones de consumidores, como necesarios contrapeso al poder de los monopolios y de las grandes multinacionales.

Puesto que desde fines del siglo XIX y más aún después de la Segunda Guerra Mundial, la libre competencia es una falacia y las grandes corporaciones monopolistas dominan los resortes fundamentales de la economía, se debe ir hacia un nuevo Estado industrial que, mediante planificación, suministre bienes y servicios en cantidades adecuadas a la sociedad y vele por objetivos que no sean puramente económicos ${ }^{45}$.

Los gobiernos aplicaron, en mayor o menor medida, estas tesis, que cristalizaron en el Estado del bienestar. El objetivo último del Estado del bienestar es lograr la igualdad económica de los ciudadanos mediante me-

\footnotetext{
44 J. K. Galbraith, La economía mundial: Presente y perspectivas de futuro, Ayuntamiento de Oviedo, Universidad de Oviedo, 1992, pp. 15-16.

45 J. K. Galbraith, El nuevo estado industrial, Barcelona, Orbis, 1986, pp. 13-15
} 
canismos de distribución de la riqueza, ya que la igualdad política se considera lograda en las democracias parlamentarias ${ }^{46}$. La política económica del Estado del bienestar se caracterizará por el crecimiento continuo del gasto público para atender las necesidades sociales ${ }^{47}$.

En Estados Unidos, terminada la guerra, el Estado conservaría cierto papel directivo de la economía. En 1946, el Congreso aprobó la «Employment Act", que suponia la planificación de la política de empleo ${ }^{48}$. Los republicanos aceptaron el creciente papel del Estado para poder mantener una poderosa defensa militar contra el comunismo. Pero, al mismo tiempo, el gasto público financiaba la educación, la vivienda, la sanidad, el paro, los precios agrarios, etc. ${ }^{49}$. Entre 1961 y 1968 , Kennedy y Johnson reforzaron la política keynesiana, aplicada por economistas como P. A. Samuelson, W. H. Heller y J. K. Galbraith. Antes de la llegada de Kennedy al poder, el Estado empleó fondos para atender el desempleo y sostener los mercados agrícolas; se proponía evitar las crisis y las recesiones. La administración demócrata aplicará una política más genuinamente keynesiana ${ }^{50}$ : restablecimiento del pleno empleo y distribución de la riqueza con medidas propias del Estado del bienestar. El mayor problema de la economía norteamericana, sobre todo a partir de 1966, fue la inflación. Las medidas de desaceleración económica para atajarla redujeron el crecimiento. Finalmente, se tuvo que renunciar a la expansión. Los desequilibrios de tipo fiscal, financiero, monetario, presupuestario, etc., inducidos por la inflación, condujeron a la crisis de 1973.

En Inglaterra, el modelo de sociedad nueva sería el "Welfare State», basado en el plan del político radical Beveridge, que fue adoptado por los laboristas. Este plan garantizaba la protección social de los ciudadanos a lo largo de su vida: medicina, subsidio de desempleo, vivienda, educación, etc. El gobierno preparó un plan económico y nacionalizó sectores básicos como el Banco de Inglaterra, el carbón, los transportes y el acero. Los conservadores, en el poder desde 1951 a 1964, mantuvieron lo esencial del «Welfare State», que recibió nuevo impulso con el laborista Wilson: creación de un Ministerio de Economía para programar la economia y de una sociedad estatal, la “Industrial Reconstruction Corporation», para ha-

\footnotetext{
46 Julio Segura, Francisco Cabrillo y Gabriel Tortella, La reforma del Estado asistencial, Madrid, Centro de Estudios Constitucionales, 1987, p. 17

47 Giuseppe Mammarella, Historia de Europa Contemporánea (1945-1990), Barcelona, Ariel, 1990 , pp. $249-50$.

48 J. K. GalbRaith, La era de la incertidumbre, pp. 219-22.

49 J. K. Galbraith, La sociedad opulenta, Barcelona, Planeta, 1992, pp. 14-15.

50 P. Delfaud, et al., ob. cit., pp. 641 y ss.
} 
cerse cargo de sectores en los que no invirtiese la iniciativa privada o interesasen al Estado ${ }^{51}$.

Francia optó por la planificación indicativa, que, sirviéndose de los mecanismos del mercado, ofrecía instrumentos al gobierno para utilizar los recursos y corregir los efectos no deseados. El gobierno fijó objetivos, armonizó el crecimiento, organizó los mercados, creó y financió empresas, reguló el mercado laboral, desarrolló servicios sociales, concedió créditos y subvenciones, otorgó ventajas fiscales, etc. En Japón, la reconstrucción se hizo bajo el control del gobierno mediante créditos, incentivos fiscales y adjudicación de materias primas. Los bancos y los grandes grupos industriales estaban tutelados por el Estado, que protegió la industria con elevados aranceles. En Alemania se puso en práctica la "economía social de mercado" ("Soziale Markwirtschaft»), una orientación más liberal de la economía, aunque atendiendo a las necesidades sociales de la población e interviniendo en los sectores en los que existiese cierto desequilibrio entre oferta y demanda.

El desarrollo español también transcurrió por la vía de los planes de desarrollo indicativos y la práctica del "stop and go", con un control muy fuerte de la economía por parte del Estado. Desde el punto de vista tecnócrata el Estado sería una “empresa de empresas». En todo caso, la planificación supuso una liberalización frente al intervencionismo prácticamente total de la economía del período anterior. Los mercados agrícolas estaban intervenidos por una larga serie de instituciones. EI INI nació para financiar las empresas estatales en el sector industrial. El comercio exterior estaba intervenido mediante licencias de importación, subvenciones a la exportación, proteccionismo aduanero, tipo de cambio de la peseta, etc. El intervencionismo en asuntos sociales era absoluto: organización sindical dependiente, rigidez del mercado de trabajo, regulación de salarios, prohibición de la huelga y control de la seguridad social con la intención de proporcionar una seguridad total en la línea del Estado del bienestar, como justificación social del régimen.

En la línea argumentativa que estamos desarrollando, continúa el ciclo de control económico y político que comienza a finales del siglo XIX y que se consolida a partir de 1920. Con el intervencionismo en lo económico prosiguió la necesidad de mayor control político. En los países en los que peligraba la estructura económico-social se limitó la libertad en todos los ámbitos y se propició el predominio de los sistemas autoritarios. Fuerzas

51 G. Mammarella, ob. cit., pp. 52-53 y 266-67. 
nacionales e internacionales actuaban en este sentido. Si no se controlaba el aparato político desde la derecha, otras fuerzas lo harian desde la izquierda, puesto que el sistema requería una dirección estrecha de la economía, de las fuerzas productivas y de los mecanismos políticos. $Y$ esto era así porque las teorias económicas vigentes propugnaban que el Estado planificase, nacionalizase, invirtiese, crease empresas públicas, subvencionase empresas privadas, regulase empleo, demanda, precios y salarios, atendiese a las necesidades sociales, etc.

En toda la Europa del este se instauraron regímenes soviéticos después de la Segunda Guerra Mundial, justificados precisamente por la necesidad de que el Estado se apropiase de los medios de producción y planificase la economía.

Portugal y España continuaron con sus dictaduras de anteguerra, ensayando, primero, esos sistemas de economía mixta propugnados por los fascismos y aplicando, más tarde, la planificación indicativa. En Grecia, tras un largo periodo de inestabilidad social y política, los militares establecieron una dictadura con el apoyo de los Estados Unidos y de la OTAN.

En América Latina se alternaron regímenes civiles y militares. Después de la guerra continuaron muchas de las dictaduras del período de entreguerras. Hubo cierto ascenso de las democracias durante los años cincuenta. Pero a partir de los sesenta muy pocos países mantuvieron el régimen democrático. Se sucedieron los golpes en Brasil, Argentina, Perú, Chile, Uruguay y en la mayor parte de los países del área, como reacción a la revolución cubana y la expansión de la guerrilla comunista, con la inestimable ayuda de los Estados Unidos. A partir de 1964 sólo conservaron el sistema democrático sin interrupciones Venezuela, Colombia y Costa Rica. Hasta países tradicionalmente democráticos como Chile y Uruguay sufrieron la dictadura militar.

\subsection{Segundo ciclo: Las políticas neoliberales y la expansión de la democracia}

\section{II.2.1. Tipicidad de las crisis de los setenta y de los ochenta}

Las recesiones entre 1945 y 1973 fueron escasas y poco profundas. Después se sucedieron la crisis de 1973, la recesión mundial de 1974-75, la crisis de 1979 y las tensiones financieras de los ochenta y noventa.

El crecimiento económico mundial había estado basado en una energía barata y en la estabilidad monetaria y de los tipos de cambio. Al quebrar 
estos dos pilares sobrevino una crisis cuyos rasgos eran diferentes a las precedentes ${ }^{52}$.

En 1973 comienza una crisis de ciclo largo. Tras unas primeras medidas de ajuste, hubo cierta recuperación económica entre 1976 y 1979. En este año tuvo lugar una segunda crisis del petróleo. La economía entró en una profunda crisis con altas tasas de inflación hasta su nuevo relanzamiento a partir de 1982. Aún hubo dos importantes crisis bursátiles en 1987 y 1989. Desde la segunda mitad de 1997 los países asiáticos emergentes padecen una grave crisis financiera. La crisis alcanzó también a Japón y a América Latina y amenaza las bolsas occidentales. Los problemas económicos de Rusia, agudizados en 1998, también repercuten negativamente en EEUU y Europa.

A pesar de las crisis, en estos años, a diferencia de lo que ocurriera tras la crisis de 1929, la economia mundial experimentó un importante desarrollo: a principios de los noventa la producción global era el doble de la de principios de los setenta. No obstante, persiste el paro en los países desarrollos y el hambre en los subdesarrollados.

No se cumplia la ley o curva de Phillips. Este economista británico había observado que en Gran Bretaña, entre 1861 y 1957, los precios y los salarios bajaban cuando el paro subía. También observó la relación entre salarios y precios, que subían y bajaban a la vez por la influencia de aquéllos en éstos. El subempleo aminoraba las subidas salariales; por tanto, para luchar contra la inflación bastaba con frenar la actividad económica y crear subempleo. Pero, a partir de los setenta esta ley no se cumplía. El estancamiento económico producía paro, pero también inflación ${ }^{53}$.

Las nuevas tecnologías, la informática, la telemática, la robótica, a diferencia de otras épocas parece que sólo pretendan ahorrar costos ahorrando mano de obra. Paradójicamente, cuanto más se invertía más empleo se suprimía. El paro se ha convertido en un rasgo estructural, se mantiene incluso cuando hay crecimiento. Es mucho más grave que el de los años treinta, porque dura ya más de veinte años, no se vislumbra solución, el trabajo que se crea es precario y no hay dinero suficiente para asistir a los numerosos desempleados.

Las causas eran variadas. A las nuevas tecnologías, en especial la robotización, habia que añadir la competencia de los paises emergentes

52 Banco de Santander, Informe económico 1973, 2 trimestre, Madrid, junio de 1973, pp. 1-4. BANCO EXTERIOR DE ESPAÑA, Boletín mensual de información económica, Madrid, agosto-septiembre 1973, pp. 9-11.

53 A. GÉLEDAN, ob. cit., pp. 152-53. 
con bajos costos y el crecimiento demográfico de las décadas de los cincuenta y sesenta. Las consecuencias son preocupantes: menos cotizantes a la seguridad social, más subsidios y por tanto reducción de otras prestaciones y del Estado del bienestar.

La gran novedad es la aparición de la estanflación, que obligaba a aplicar remedios en muchos casos contrarios a los que se adoptaron en la depresión de los años treinta. Mientras que en 1929 habia que incentivar la demanda, ahora había que tomar medidas de contención de la misma para dominar la inflación, pues en caso contrario se perdería competitividad; mientras que en 1929 se propugnaba el déficit, ahora era prioritario rebajarlo.

Debido a todas estas diferencias existía una gran confusión entre los economistas, que no sabian manejar una crisis en la que la caída de la producción fuese acompañada de fuertes subidas de precios. Así como la crisis de 1929 rompió el esquema liberal, la de 1973 rompió el keynesianismo, que se mostró ineficaz para controlar esta crisis ${ }^{54}$.

\subsubsection{Del keynesianismo al monetarismo}

El mundo empezó a cambiar a principios de los setenta y gran parte de las tesis de Keynes empezaron a ser superadas. Ya no se podian mantener los gastos e inversiones del Estado del período de crisis de los años treinta porque entonces, en vez de inflación, había deflación, ni de las décadas posteriores a la Segunda Guerra Mundial, porque los ingresos del Estado eran inferiores y los gastos superiores.

Hasta un keynesiano tan convencido como Galbraith, aun siendo partidario de mantener algunos de los principios de Keynes, comprende que algunas de sus tesis han de ser olvidadas en el nuevo ciclo. En una de sus primeras obras tras la crisis de 1973, Galbraith admite que el remedio keynesiano era asimétrico: "surtía efecto contra el desempleo y la depresión, pero no contra la inflación» ${ }^{55}$. A pesar del desempleo, la inflación no podía ser contenida, cuando Keynes había pronosticado que la inflación se controlaría sin dificultades si había suficiente desempleo. $\mathrm{H}$. van der Wee sostiene que la economía mixta se había transformado en casi todos los paí-

54 Luis GAMIR, "Nota introductoria» en VVAA, Política Económica de España, coordinado por Luis Gámir, 5. ed., Madrid, Alianza, 1986, pp. 23-26. Enrique FuENTES QuintanA, La crisis económica actual: sus problemas y soluciones, Cádiz, UNED-Cádiz, 1977, p. 18.

55 J. K. Galbraith, La era de la incertidumbre, p. 224. 
ses en «un dirigismo pragmático» dependiente de estructuras burocráticas y de intereses corporativistas: la recesión de los años setenta no podía ser superada en este marco tan encorsetado y tan poco flexible.

Con la escasez relativa de materias primas y el aumento de las presiones salariares, las recetas keynesianas provocaban distorsiones y tensiones inflacionistas graves. La inflación restaba competitividad y posibilidades exportadoras a los países. Por tanto, era prioritario acabar con la inflación, pero las fórmulas keynesianas se revelaron inadecuadas para combatirla.

El cambio de política venía exigido también por el dinamismo propio del sistema económico: las industrias básicas y buena parte de las de consumo se desplazaban de los países viejos a los jóvenes, que no soportaban los gastos sociales de los países industrializados, tenían mano de obra abundante y barata y ofrecian zonas francas con subvenciones $y$ bajos impuestos y cuya gestión industrial era más ágil y flexible ${ }^{56}$.

Tras casi todo un siglo $x x$ de intervencionismos, sistemas de economía mixta y Estados del bienestar, en el último cuarto de esta centuria llega de nuevo el liberalismo. Una de las máximas defensoras de las nuevas corrientes liberales, la que fuera primera ministra del Reino Unido, Margaret Thatcher, basa sus preferencias por el libre mercado en su eficacia para crear riqueza, muy superior a la de cualquier otro sistema: el mercado libre es un enorme y sensible sistema nervioso que responde a "sucesos y señales en todo el mundo" mientras que los gobiernos actúan «sobre un volumen más reducido de información" y andan dando traspiés y obstaculizando las operaciones del mercado. La economía después de la Segunda Guerra Mundial se encontraba «devastada por el socialismo estatal» 57.

Ante la ineficacia de la economía mixta y del keynesianismo para dar respuesta a los problemas económicos de la década de los setenta, los economistas neoclásicos (Mises, Hayek) y monetaristas (Friedman, Brunner) propugnaban la vuelta a la economía de mercado. Se oponian a la mala administración pública y a la acumulación de poder económico en manos del Estado. Los acuerdos entre interlocutores sociales y económicos y el Estado distorsionaban el mercado y alentaban el desarrollo de las estructuras corporativas y burocráticas ${ }^{58}$. Sólo reduciendo el poder de los sindicatos se lograría mayor productividad y mayor progreso econó-

56 J. K. Galbraith, La economía mundial: Presente..., pp. 10-11.

57 Margaret ThatCheR, Los años de Downing Street, Madrid, Aguilar, 1994, pp. 22-23.

58 H. VAN DER WEE, ob. cit., pp. 397 y ss. 
mico. Las cargas salariales y las leyes laborales disminuyen los beneficios de las empresas y el incentivo para invertir, a la vez que contribuyen a la pérdida de competencia con respecto a los mercados emergentes del Tercer Mundo. Si se somete el mercado a criterios éticos, como la distribución de la riqueza, se destruye la objetividad del proceso económico, pues los criterios de distribución pueden ser determinados subjetivamente. El mercado libre, sin embargo, es neutral: se remunera a los individuos en función de su eficacia económica, no de la decisión de la burocracia ${ }^{59}$.

La empresa pública no busca sólo resultados económicos; en ocasiones incluso los sacrifica. El norteamericano James Buchanan es uno de los principales desveladores del papel del Estado en nuestra sociedad. La libertad de elección de los individuos es obstaculizada por las elecciones que hace el Estado en su nombre obteniendo y administrando sus impuestos ${ }^{60}$. Friedman concede que, en sus comienzos, el Estado del bienestar era soportable, porque los contribuyentes eran muchos y los que lo necesitaban pocos. Pero en cuanto aumentaron los programas de bienestar, las cosas empeoraron.

La única solución al nuevo fenómeno de la estanflación sería una política monetaria correcta. Las fuerzas autorreguladoras del mercado llevarían a la economía a la estabilidad de precios, pero para ello el Estado habría de seguir una política monetaria según reglas fijas, puesto que la inflación está provocada por el crecimiento más rápido de la cantidad de dinero que de la producción ${ }^{61}$. Por tanto, la mejor política monetaria era «incrementar la oferta monetaria a ritmo constante, pero lento", cada año. El control de la inflación puede ocasionar temporalmente un crecimiento más lento, pero pasado un tiempo incidirá favorablemente en la producción, mientras que mantener la inflación sólo retrasaría el problema y la caída de la producción sería más dura. Los problemas de inflación y crecimiento lento proceden del gasto excesivo y del intervencionismo del Estado, que obstaculizan el ahorro y la inversión. Un Estado que gasta demasiado sube los impuestos. Esto lleva a la creación de dinero, que trae la

59 Milton y Rose Friedman, Libertad de elegir. Hacia un nuevo liberalismo económico, BarceIona, Planeta-Agostini, 1993, p. 342 y Friedrich A. HAYEK, Los fundamentos de la libertad, Madrid, Unión Editorial, 1991, pp. 334-41.

60 James M. BuChanan, “Política sin romanticismos. Esbozo de una teoría positiva de la elección pública y de sus implicaciones normativas" en J. M. BuCHANAN, R.E. MCCORMick y R. D. TOLLISON, El análisis económico de lo político: Lecturas sobre la teoría de la elección pública, Madrid, Instituto de Estudios Económicos, 1984, pp. 105-135.

61 M. FRIEDMAN, La economía monetarista, p. 65. H. VAN DER WEE, ob. cit., pp. 397-98. 
inflación. El gasto y el intervencionismo reducen el crecimiento de la producción ${ }^{62}$.

El problema de la inflación ha terminado por inclinar a los gobiernos a imponer tasas bajas de crecimiento monetario para controlarla, con cierto desprestigio del ajuste fino fiscal. Una inflación bajo control aumenta el atractivo para las inversiones en renta fija y la perspectiva de que los tipos de interés se mantengan bajos es una buena noticia para los negocios. Otra de las formas de controlar los precios es el uso de cláusulas de indexación, consistente en descontar la inflación en contratos, impuestos, créditos, etc. ${ }^{63}$.

El relanzamiento de la economía no se dará más que con un renacimiento de las inversiones. Pero no se preparará una expansión sana ofreciendo subvenciones a los inversores o estimulando la demanda con altos salarios o la intervención del Estado. Sólo se logrará aumentando la productividad, capitalizando las empresas y reduciendo los costos.

\subsubsection{El triunfo de la política económica neoliberal}

Durante los años setenta empezaron a difundirse las ideas monetaristas de estabilidad, contención de la masa monetaria y política presupuestaria equilibrada. Muchos gobiernos elaboraron su política macroeconómica basándose en los principios monetaristas. En líneas generales, las medidas que adoptaron los países desarrollados se inspiraron en dos principios: $1^{\circ}$ El modo más eficaz para reorganizar la economía es el mercado libre. $2^{\circ}$ Los mayores enemigos del mercado son la excesiva intervención del Estado y los monopolios, que impiden el libre desarrollo del mercado ${ }^{64}$. La aplicación de estos principios suponía una vuelta al liberalismo económico y el triunfo de la teoria neoliberal.

Los paises occidentales adoptaron medidas antiexpansionistas y antiinflacionistas: $1^{\circ}$ Limitación de gastos presupuestarios (contención del aumento del personal empleado, disminución de las prestaciones sociales y de las subvenciones, reducción de los gastos de obras públicas, mantenimiento de los impuestos, etc.). $2^{\circ}$ Control del dinero en circulación y del

\footnotetext{
62 J. M. BUCHANAN, "Límites constitucionales al poder fiscal del Estado" en El análisis económico de lo político..., pp. 137-72.

63 M. Friedman, ob. cit., p. 36.

64 E. Bono, J. A. Tomas y G. Muñoz, "Política de calidad de vida" en VVAA, Política económica de España, p. 532.
} 
crédito. $3^{\circ}$ Vigilancia de los precios. $4^{\circ}$ Moderación de los salarios. $5^{\circ} \mathrm{De}-$ volución al sector privado de empresas del sector público ${ }^{65}$.

Antes de la llegada de Reagan a la presidencia de los Estados Unidos, se ensayaron distintas políticas económicas, en muchos casos contradictorias, que terminaron en el fracaso. Reagan llegó al poder en 1980 dispuesto a poner en práctica una política económica ultraliberal. Esta doctrina se apoyaba en unas ideas simples: estimular la producción alentando la inversión mediante la reducción de impuestos. La pérdida de ingresos del Estado sería compensada por la disminución de sus gastos y por la aceleración del crecimiento. Su programa también proponía pagar la energía a precios reales y eliminar todo tipo de trabas a la iniciativa privada. Logró que el Congreso aceptase el descenso de los gastos en todas las partidas presupuestarias, sobre todo en las sociales. Las nuevas disposiciones fiscales rebajaron los impuestos de las personas físicas en un $25 \%$.

A su vez, Paul Volcker, presidente de la Reserva Federal, se propuso atacar el problema de la inflación mediante un control estricto del crecimiento de la tasa monetaria, aun con el riesgo de que se resintiese la actividad económica. Subió los tipos de interés hasta el $21,5 \%$ (después bajaron lentamente) y aminoró el ritmo de crecimiento de la cantidad de dinero hasta el 6-7\%. En el espacio de dos años, 1980-82, la tasa de inflación pasó del 10 al $4 \%$.

El crecimiento económico no tardó en llegar. Entre 1983-84 el PIB creció por encima de los demás paises, exceptuando Japón, el dólar acentuó su posición hegemónica mundial, mejoró la productividad y rentabilidad de las empresas y afluyeron capitales de todas las partes del mundo atraídos por los altos tipos de interés ${ }^{66}$.

A pesar de los recortes habidos en el Estado del bienestar durante los mandatos de Reagan, Clinton preparó una nueva ley para reformarlo y crear un sistema que estimule a la ocupación de los puestos de trabajo, pues se piensa que el exceso de gastos sociales no es la solución sino la causa del círculo vicioso, que conduce a una situación insostenible: ingresos mínimos proporcionados por el Estado, pobreza, marginación, delincuencia. Muchos no ocupan un puesto de trabajo para no perder el cheque del Estado. Clinton ha señalado el 2002 como año tope para lograr el equi-

65 L. GAMIR, «Algunas ideas sobre la crisis económica» en Información Comercial Española, $n^{\circ}$ 617-618, en.-feb. 1985, p. 48.

66 A. Martínez Estévez, Diez aos de crisis en la economía mundial, Madrid, I.E.E., 1985, pp. $37-38$ y 55 . 
librio del presupuesto norteamericano a base de ahorro público e incremento de la producción y del empleo ${ }^{67}$.

En Inglaterra el gobierno conservador de $\mathrm{M}$. Thatcher «imprimió un cambio histórico" en la economía y la sociedad ${ }^{68}$. Su programa consistía en el control de la oferta monetaria para reducir la inflación; restricción del gasto público; reducción del impuesto sobre la renta, traspasando la imposición sobre el ingreso a la imposición sobre el gasto; reducción del empleo en el sector público y congelación de salarios en la administración; privatización de empresas y servicios públicos; reforma de la seguridad social mediante el autogobierno y responsabilidad presupuestaria de los hospitales y el aumento de gravámenes en las recetas médicas; reforma sindical y del empleo quebrando el poder de los sindicatos, abaratando los despidos y reduciendo los costes salariales ${ }^{69}$. El gobierno Major continuó la política neoliberal de su antecesora. Tony Blair, a pesar de su mayor sensibilidad social, está dispuesto a frenar la dependencia de los subsidios y a recortar los gastos de la seguridad social. Con ello pretende propiciar el trabajo y la creación de riqueza. Los principios que rigen esta tapa del laborismo son estabilidad económica, menor intervencionismo del gobierno que se ha de centrar en la educación y la creación de infraestructuras, reforma del sistema de bienestar, descentralización del Estado e internacionalismo ${ }^{70}$.

Helmut Kohl llegó al poder en Alemania en 1982. Al principio el giro respecto a la política socialdemócrata fue muy limitado. Después, los recortes y las privatizaciones se han incrementado: disminución de las cargas sociales de las empresas, que alcanzaban más del $40 \%$ del salario bruto y reducción, en unos veinticinco mil millones de marcos, de los gastos sociales del Estado. Por otro lado, Alemania se ha visto obligada a llevar a cabo el mayor esfuerzo privatizador de su historia con la privatización de la economia de la RDA concluida en 1994. También en la antigua RFA se han privatizado numerosas empresas. Se pretende privatizar todo sector que no tenga un interés de primer orden para la sociedad y el Estado y desprenderse de cualquier empresa que tenga pérdidas ${ }^{71}$.

Sólo Francia y algunos países mediterráneos mantuvieron durante algún tiempo una tendencia opuesta. Los socialistas franceses llegaron al

\footnotetext{
67 Véase El País, 2 junio 1996, p. 51 y 4 agosto 1996, p. 4.

68 Véase G. Mammarella, ob. cit., p. 368.

69 Resumen de las ideas más importantes contenidas en el libro de M. THatcher, Los años de Downing Street.

70 El Pais, 3 junio 1997, p. 29 y 8 febrero 1998, p. 4.

71 Véase el suplemento de negocios El Pais, 14 julio 1976, p. 4.
} 
poder en 1981. También en España, Grecia y Portugal ganaron las elecciones los socialistas. Pero la política de austeridad requerida por la crisis y la competencia internacional indujeron a estos gobiernos a abandonar la política de gastos sociales y salarios altos y adoptar las estrategias neoliberales. El gobierno Juppé había planteado recortar el gasto público en 1997 en un 1,7\%, unos setenta mil millones de francos, el mayor recorte de la $V$ República francesa. Tras su triunfo en las elecciones de 1997, el gobierno de Lionel Jospin ha intentado imprimir mayor flexibilidad a la política económica. Su propuesta más novedosa para crear empleo ha sido la semana laboral de 35 horas, que se implantaría de forma general en el año 2002, aunque sólo en el sector privado, puesto que en el público generaría demasiado gasto y sería necesario aumentar los impuestos ${ }^{72}$.

En otras muchas naciones europeas como Dinamarca, Finlandia, Irlan$\mathrm{da}$, Islandia o Malta los socialdemócratas dejaron paso a los conservadores. Incluso Suecia, paradigma durante décadas del Estado del bienestar, se ha visto obligada a sucesivos programas de ajuste que han recortado drásticamente las prestaciones sociales.

La política de ajuste se ha llevado de forma muy estricta durante bastantes años. Los paises de la UE aprobaron en Maastricht un programa restrictivo en cuanto a reducción del déficit público, inflación, deuda y tipos de interés. El rigor en la aplicación de los duros criterios de Maastricht parece estar provocando una reacción en el electorado europeo, muy evidente en la mayor parte de los procesos electorales que se desarrollaron en 1977. El triunfo de los laboristas en el Reino Unido y de la izquierda en Francia debe interpretarse como un deseo de los ciudadanos de que se adopten políticas más sociales y de que se ponga fin el desmontaje del Estado del bienestar.

Japón es uno de los pocos países de economía de libre mercado que no siguió una política de ahorro público, aunque en los períodos depresivos también aplicó políticas duras de ajuste. Después de una recuperación espectacular durante los años ochenta, en los noventa decidió aumentar los presupuestos generales para apoyar la recuperación aún a costa de hacer crecer su deuda pública. La crisis japonesa de 1997-98 estuvo directamente conectada con la de los países emergentes debido a sus inversiones en el área y a la caída de sus exportaciones hacia esos países. Pero también contribuyeron las deficiencias del sistema financiero japonés plagado de rigideces y fuertemente intervenido por el Estado. Las

72 El Pais, 2 junio 1996 p. 50 y 3 junio 1997, pp. 1-5. ABC, 15 junio 1997, p. 39. 
respuestas, más políticas que económicas, precipitaron la quiebra de importantes bancos y la caída de la bolsa ${ }^{73}$.

El futuro es imprevisible. La evolución histórica exigirá nuevas respuestas económicas y políticas, teniendo siempre en cuenta que «la condición de supervivencia del sistema capitalista es una continua renovación y reconversión de las fuerzas productivas, en la cual el elemento primordial lo constituye la necesidad de competir por un mercado del que se espera aporte por sí mismo una regulación suficiente de la vida socioeconómica» ${ }^{74}$.

11.2.4. La doctrina política neoliberal: relación entre libertad económica y libertad política

La doctrina neoliberal trata el sistema político de modo simétrico al económico: "Ambos se consideran mercados en los que el resultado se determina a través de la interacción de personas que persiguen sus propios intereses" "75. Friedman pone el ejemplo de Estados Unidos, donde el éxito tanto de la libertad política como de la libertad económica está basado en dos conjuntos de ideas que no tienen sentido el uno sin el otro, las expresadas por $\mathrm{A}$. Smith en La riqueza de las naciones y las de la Declaración de la Independencia redactada por $\mathrm{T}$. Jefferson ${ }^{76}$.

F.A. Hayek ha intentado demostrar la incompatibilidad entre socialismo y libertades políticas, puesto que este sistema exige un plan que determine las necesidades y un parlamento es lo menos apropiado para tal cosa; la democracia sólo es posible en el liberalismo, que limita el número de cuestiones sobre las que hay que estar de acuerdo dentro del Estado y cada individuo es libre para determinar sus necesidades en un sistema que descansa en la competencia y la propiedad privada ${ }^{77}$. Aunque Schumpeter compatibiliza socialismo y libertad, también pone de manifiesto que la democracia liberal, unida a los intereses de la burguesía, encuentra dificultades para mantenerse con un Estado intervencionista ${ }^{78}$.

El Pais, 2 junio 1996 p. 51 y 30 noviembre 1997, p. 18.

74 F. Garcia de Cortazar y J. M. Lorenzo Espinosa, Historia del mundo actual, Círculo de Lectores, 1994, p. 304.

75 M. y R. FRIEDMan, Libertad de elegir, pp. 9-10.

76 Ibidem, p. 19.

77 Véase F. A. HAYEK, Democracia, justicia y socialismo, Madrid, Unión Editorial, 1985 y La fatal arrogancia: los errores del socialismo, Madrid, Unión Editorial, 1990.

78 J. A. SCHUMPETER, Capitalismo, Socialismo y Democracia, Barcelona, Ediciones Folio, 1984, p. 377. 
Los obstáculos a la libertad económica limitan la libertad en general y también las libertades específicas, como la de prensa o la de expresión. Quien espera una subvención o cualquier otro beneficio económico o corre el peligro de que se la retiren, difícilmente va a criticar la política del gobierno por muy en desacuerdo que esté ${ }^{79}$.

Concluye M. Friedman que "una sociedad que anteponga a la libertad la igualdad (...) acabará sin una ni otra" ${ }^{80}$. Si se usa la fuerza para lograr la igualdad, se destruye la libertad; si se otorga la fuerza a un grupo de personas más o menos amplio acabará por utilizarla en su beneficio. Si se antepone a todo la libertad, el resultado será más libertad y mayor igualdad. Así lo demuestra hasta ahora la historia pasada y presente: ha existido y existe más igualdad donde ha existido o existe más libertad ${ }^{81}$.

En apartados anteriores hemos analizado cómo los países democráticos liberalizaron sus estructuras económicas y abandonaron muchas de las prácticas intervencionistas para superar la crisis y retomar el tren del crecimiento. Para conseguir esos mismos objetivos con la puesta en vigor del mismo conjunto de medidas, los países autoritarios necesitaron compaginar liberalización económica y liberalización política, cumpliéndose el principio de que la interdependencia entre libertad económica y libertad política es una característica del mundo actual.

11.2.5. Las transiciones en el sur de Europa. La transición democrática española

Los países del sur de Europa tuvieron un desarrollo económico tardío. En muchos de ellos la democracia nunca llegó a consolidarse del todo. A las fases democráticas seguian otras autoritarias. Si observamos la Europa meridional como un todo, «la solución fascista o fascistizante en esta parte del mundo tiene que ser entendida como un fenómeno contrarrevolucionario fundamental de "onda larga"» ${ }^{32}$. En los años setenta comienza otra onda larga de signo contrario. El contexto internacional era favorable a la democratización. Los EEUU y la CEE apoyaron este proceso.

79 M. y R. Friedman, ob. cit., pp. 101-102.

80 Ibidem, p. 209.

81 Ibidem.

82 Salvador GINER, “La economía politica, la legitimación y el Estado en la Europa meridional” en Guillermo O'DONNELL, Phillipe C. SCHMITTER y Laurence WHITEHEAD (compiladores), Transiciones desde un gobierno autoritario, 4 vols., Barcelona, Paidós, 1994, vol. I, pp. 30-32 y 47. 
La industrialización, el aumento de las clases medias, el proceso de urbanización en las décadas posteriores a la Segunda Guerra Mundial, crearon las condiciones para que Grecia y Portugal transitaran a la democracia. Crisis de diverso tipo, políticas, económicas, militares, a veces sumadas, contribuyeron al derrumbamiento de estas dictaduras durante los años setenta. Las transiciones en el sur de Europa respondían a «la necesidad de nuevos horizontes políticos para enmendar las respectivas situaciones críticas internas, influidas por una idéntica dependencia de los acontecimientos económicos internacionales» ${ }^{83}$. El proceso se llevó a cabo mediante el consenso entre la izquierda, que abandonó sus propuestas revolucionarias, y una derecha, que aceptó muchos de los presupuestos de la izquierda. Establecida la democracia se procedió a la liberalización de las instituciones económicas y al ajuste de los indicadores básicos con el fin de integrarse en la CEE. Para ello hubo que desmantelar monopolios y privatizar empresas. El capital extranjero se hizo con muchas de las empresas, aumentando la interconexión y subordinación al capitalismo internacional ${ }^{84}$.

En España, en la década de los sesenta, la estructura social y económica experimentó un constante proceso de modernización, en la que se basará la posterior democratización. Los cambios económicos y sociales no habían ido acompañados de cambios políticos sustanciales. Para dar un salto en el crecimiento económico era preciso transformar el sistema político, pero también la economía exigía aún cambios de envergadura; para comprender la necesidad de reformas económicas hay que tener en cuenta la gravedad de la crisis de 1973, que, más allá de una simple crisis cíclica, era, en España, una crisis estructural.

Hasta entonces se ignoraban en buena medida los mecanismos de la economia de mercado. Para integrarse plenamente en las corrientes económicas internacionales, pasar a una economía más competitiva y superar un modelo de desarrollo que no podía dar más de sí, se necesitaban una serie de reformas estructurales.

Con la crisis económica y la difícil situación política de la transición, la situación se agravó. Hubo un retraso en la toma de medidas correctoras al darse prioridad a los problemas políticos sobre los económicos; para reducir tensiones no se hicieron los ajustes duros necesarios, puesto

\footnotetext{
83 F. Garcia de cortazar y J. M. Lorenzo Espinosa, ob. cit., p. 238.

34 S. GINER, ob. cit., pp. 32-33.
} 
que el tardofranquismo y la transición exigían paz social ${ }^{85}$. Reformas tan complejas, que afectaban a todos los sectores sociales, no podían abordarse sin consenso político y social y esto sólo era posible con el cambio democrático.

El Estado democrático parlamentario permite «modificaciones de las relaciones de fuerzas en el seno del bloque en el poder sin grave trastorno de los aparatos del Estado" ${ }^{86}$, papel que no pueden cumplir las dictaduras. Las modificaciones en las relaciones de fuerzas ponen en peligro más a las dictaduras que a las democracias.

Los sectores más clarividentes del empresariado español consideraban que el sindicato vertical era un obstáculo y que era necesario pactar con los sindicatos ilegales. Los sindicatos de clase clandestinos repudiaban el pacto social con un gobierno no democrático y se relanzó un movimiento obrero que apuntaba hacia objetivos salariales y sindicales, pero también políticos ${ }^{87}$. Los empresarios estaban preocupados por el futuro político. Coincidian en la necesidad de un cambio político para resolver los problemas sociales, sobre todo el deterioro de las relaciones laborales; ante todo estaban preocupados por saber si se cumplirían las condiciones políticas que permitieran el pacto social y la integración en la CEE ${ }^{88}$.

También grupos políticos conectados directa o indirectamente con el régimen, convencidos de la necesidad de una evolución politica como solución para la modernización de la economía y la integración en la CEE, constataban el deterioro de las relaciones laborales, la falta de representatividad de los sindicatos verticales, la escalada de la conflictividad laboral y la imposibilidad de un pacto social.

Cuando, a causa de la crisis económica, se redujeron los beneficios de las empresas y muchas de ellas comenzaron a tener pérdidas, se recrudecieron los problemas de financiación y modernización de equipos y aumentaron las tensiones por reivindicaciones salariales, los grupos empresariales más dinámicos propugnaron la democratización política, la li-

85 L. GamIR, "Nota introductoria" en VVAA, Política económica de España, pp. 23-26. E. Fuentes Quintana, ob. cit., pp. 19 y 21. R. TAMAMES, "El otoño de la economía española" en Cuadernos para el Dialogo, $n^{2} 145$, octubre 1975, pp. 13-21. C. EloRDI, “Los empresarios abandonan sindicatos" en Triunfo, $n^{9} 699,19$ junio 1976, $p$. 10.

86 Nicos Poulantzas, La crise des dictadures, Paris, Maspero, 1975, p. 96

87 Cambio 16, $n^{2} 100,15$ octubre 1973, pp. 81-109 y n 209, 8 diciembre 1975, p. 15. R. MARTiN Villa, Al servicio del Estado, Barcelona, Planeta, 1975, pp. 32-35.

88 Informaciones, 13 marzo 1976, p. 12 y 20 marzo 1976, p. 9. S. Carrillo, Memoria de la transición, Grijalbo, 1983, p. 38. 
beralización de la economía, la flexibilización de plantillas, alguna modalidad de contrato temporal y el pacto social.

La adaptación a las necesidades de la nueva fase de desarrollo del capitalismo español y a la nueva relación de fuerzas no podia hacerse sin cambiar la forma de Estado. Con Arias Navarro en la presidencia del gobierno, en 1974 comenzó el proceso aperturista, que intentaba ensanchar la base política del régimen con vistas a la sucesión para perpetuar un régimen reformado bajo la Monarquía. El aperturismo fracasó estrepitosamente.

La reforma del primer gobierno de la Monarquía pretendía conservar cuanto pudiera del régimen, mantener los fundamentos del franquismo mediante una adecuación de las Leyes Fundamentales a la nueva situación monárquica. Limitaba ciertos derechos fundamentales, no concedía la amnistía, excluía a los comunistas y no admitía pactos con la oposición, sustituyendo la democracia como obra de todos por la democracia controlada.

Con Suárez se encontraron por fin los hombres y los mecanismos adecuados para transitar hacia la democracia. El cambio se hizo a pesar de la debilidad de las formaciones políticas y de la crisis económica. La estrategia seguida consistió en realizar el cambio político y ganar las elecciones primero, a costa incluso de acrecentar la crisis económica haciendo concesiones de tipo social; después se afrontaría el problema económico. Esta estrategia conformaba, por otro lado, en el plano político, dos fases: el desmantelamiento del régimen desde las instituciones, pactando con los inmovilistas, y la instauración de la democracia pactando con la oposición democrática ${ }^{89}$. Suárez supo prever y conducir los dos momentos que exigía la transición, uno sujeto a los condicionamientos del régimen y el otro democrático. El pacto con los inmovilistas se hizo a través de la Ley para la Reforma Política. A continuación el gobierno abordó la segunda fase, el pacto con la oposición democrática rupturista. Fruto del consenso, gobierno y oposición pactaron la legalización de los partidos políticos, la convocatoria de las primeras elecciones democráticas y, a continuación, la elaboración y aprobación en referéndum de una constitución democrática.

89 Suárez, como comenta Manuel Fraga, En busca del tiempo servido, Barcelona, Planeta, 1987 , pp. 22, 25, 32 y 35, supo jugar dos momentos diferenciados, uno sujeto a los condicionamientos del régimen y otro democrático. Señala J. A. DíAz-AmBronA, "Fraga y Suárez ante la transición" en Diario 16. Historia de la Transición, cap. 15, pp. 234-235, que en cada uno de esos dos momentos Suárez no partía de diagnósticos inmodificables, se plegaba a las circunstancias cambiantes. FUNDACIÓN FOESSA, Síntesis actualizada del I/l Intorme Foessa, Madrid, Euramérica, 1978, pp. 505-506. 
Ahora ya se podian abordar las reformas estructurales de tipo económico que exigía la nueva situación. Las medidas drásticas que exigia la economía sólo podría hacerlas respetar un gobierno democrático; los gobiernos predemocráticos no podían instrumentar un pacto social por el rechazo de las organizaciones políticas y sindicales democráticas. El primer intento serio llevado a cabo por un gobierno democrático con amplio consenso político y sindical fueron los Pactos de la Moncloa (1977). Las medidas de saneamiento contenidas en los pactos lograron resultados muy positivos: comenzó a controlarse la inflación, se redujo el déficit de la balanza de pagos y aumentaron las reservas de divisas. Gracias a este saneamiento económico fue posible abordar la aprobación de la constitución, la reforma fiscal y un nuevo sistema de relaciones laborales ${ }^{90}$. Después siguieron las demás reformas imprescindibles: financiera, industrial, del sector público, de la agricultura, del sector de la distribución, etc. ${ }^{91}$.

La llegada del PSOE al poder era imprescindible para completar las reformas liberalizadores. La política de saneamiento, el comienzo en serio de la reconversión industrial con la consiguiente pérdida de puestos de trabajo, el adelgazamiento del sector público, la contención de los salarios, el abandono del Estado providencia, comprendian medidas de ajuste tan duro, que, en aquella coyuntura de tanta sensibilización social, sólo podían ser aplicadas por el PSOE con al autoridad moral que entonces tenia sobre las capas sociales más desfavorecidas. Después, la política de ajuste y liberalización del PP se veria como una simple continuación de la iniciada por el PSOE. La reconversión estuvo acompañada de una política de venta de empresas públicas, que después continuaría el PP. La reconversión industrial disparó la cifra de parados debido al ajuste de plantillas que conllevaba esta política, la flexibilización del mercado de trabajo llevó el empleo a una situación de gran precariedad y la lucha contra la inflación moderó las subidas salariales ${ }^{92}$.

Pero, junto a estas medidas correctoras, el PSOE emprendió otras propias del Estado del bienestar como la universalización de la asistencia sanitaria que hasta 1984 sólo alcanzaba al $82 \%$ de la población, la reforma de la educación ampliando la enseñanza obligatoria hasta los dieciséis p. 298.

90 R. Carr y J. P. Fusı, España, de la dictadura a la democracia, Barcelona, Planeta, 1979,

91 Guillermo DE LA DEHESA, "1973-1984. La política económica frente a la crisis" en Información Comercial Espaola, $n^{9}$ 617-618, enero-febrero 1985, pp. 7-8. Banco ESPAÑOL de CRÉdito. Anuario del mercado español, 1978, p. 9.

92 Luis ALBENTOSA, "La política de ajuste aplazada: reconversión industrial" en Información Comercial Española, $n^{9}$ 617-618, pp. 175-191. 
años, el aumento significativo del número y cuantía de las becas, el incremento de equipamientos culturales y de ocio, en especial los de atención a la tercera edad. También abordó un plan de obras públicas cuyos logros más destacados fueron la mejora de la red de carreteras y la construcción de una línea del AVE y de buena parte de los $3.550 \mathrm{kms}$. de autopista proyectados ${ }^{93}$.

Correspondía al PP, tras su victoria relativa en las elecciones generales de 1996, finalizar la liberalización económica, reducir los gastos del Estado y cumplir los objetivos acordados por la Unión Europea en Maastricht, sobre todo en lo relativo a la convergencia de las economías de los paises miembros y los requisitos exigidos para acceder a la unión monetaria.

Las primeras medidas del gobierno Aznar, aprobadas en junio de 1996, pretendían impulsar la inversión con estímulos fiscales. Otras medidas liberalizaban las telecomunicaciones, el transporte, la vivienda, el suelo, la energía y los honorarios profesionales. La reforma del IRPF de 1998 aspira a reducir la carga fiscal de los contribuyentes en un $11 \%$. También se pretendía reformar el Estado del bienestar revisando las prestaciones sociales. Una de las medidas arbitradas que mayor contestación social ha encontrado es la exclusión de medicamentos de la seguridad social, peyorativamente denominada "medicamentazo". Segün lo previsto en el Pacto de Toledo, se han ido endureciendo las condiciones para acogerse a las distintas modalidades de prestación social (jubilaciones anticipadas, invalidez, etc.).

Para reducir gastos se pensó proseguir con el cierre de empresas públicas con pérdidas y continuar con la reconversión y privatización. Desde el gobierno y las instituciones financieras y económicas se insistió en la necesidad de que los aumentos salariales estuviesen en función de la productividad y que, en general, no sobrepasasen el IPC. Otra línea de actuación estaba en relación con la reducción de modalidades de contratación y abaratamiento del despido como única manera de crear empleo fijo.

La mejora del marco macroeconómico, el cumplimiento de los criterios de Maastricht, la moderación salarial y una mayor flexibilidad laboral son las claves internas del crecimiento económico de finales de la década de los noventa ${ }^{94}$.

Es fácil advertir que esta multiplicidad de reformas estaba inspirada en el pensamiento económico neoliberal y se encontraba estrechamente re-

93 Véase Alfonso Guerra y J. F. Tezanos (eds.), La década del cambio. Diez años de gobierno socialista, 1982-1992, Madrid, Sistema, 1992.

94 El Pais Negocios, 28 diciembre 1997, pp. 1-3 y 11 enero 1998, p. 14. 
lacionada con las políticas predominantes en Europa y otras partes del mundo, tanto en los países más desarrollados como en muchos de los que intentan salir del subdesarrollo.

11.2.6. La «perestroika» en la URSS y en los países socialistas del este de Europa y la liberalización de la economía china

Parece que el problema del sistema socialista es que, alcanzado cierto nivel de desarrollo económico, no puede proseguir su crecimiento sin mayor libertad a todos los niveles. Ésta es una de las razones de la liberalización generalizada del sistema en casi todos los países socialistas. R. Lew lo ha expresado con claridad: "El "socialismo real" no ha podido constituir en su propio desarrollo un modelo de funcionamiento de la economía y de la sociedad plenamente o tendencialmente coherente, es decir, que le permita reproducirse y ampliarse mediante su propio funcionamiento. Por el contrario, cuanto más ganan en complejidad los países del "socialismo real", más se atasca e incluso esclerotiza el sistema" ${ }^{95}$. Se trata del fracaso de la planificación y el dirigismo. Al carecer de mecanismos adecuados no se podían conocer los costes reales y se desaprovechaban recursos. Mientras que la economía se fijó objetivos básicos fue eficaz, pero al pasar a una economía más compleja fracasó.

La economía estaba estancada. El atraso era sobre todo tecnológico, en el terreno de la informática, de la robótica y de las comunicaciones. A principios de los ochenta la tecnología militar de los Estados Unidos era muy superior a la rusa. Y podían seguir gastando mucho más que la URSS. Esto fue evidente sobre todo a partir de la Iniciativa de Defensa Estratégica impulsada por Reagan. Gorbachov, a su llegada al poder en 1985, inició conversaciones con Reagan para acabar con la carrera de armamentos ${ }^{96}$.

Donde más fuertes fueron los esfuerzos por introducir la "perestroika» o reestructuración fue en la economía: «La primera y más importante tarea del nuevo sistema de dirección consiste en eliminar por completo el dictado del productor y el déficit en nuestra economia, y alcanzar la situación en la que la producción esté dirigida a la satisfacción de las necesidades sociales y se desarrolle según la demanda de los consumidores" ${ }^{97}$. Pau-

95 Roland LEw, China de Mao a la desmaoización, Madrid, Ed. Revolución, 1988, p. 107.

96 Véase Ronald ReAGAN, Una vida americana, Barcelona, Plaza y Janés/Cambio 16, 1991, pp. 15 y 575 .

97 Abel Aganbegyan, La perestroika económica, Barcelona, Grijalbo, 1989, p. 38 
latinamente, la industria fue privatizada. En cuanto a la reforma agraria, se aprobó la cesión de tierras a los campesinos, mediante contratos de arrendamiento de hasta cincuenta años; el objetivo era convertir a los campesinos en propietarios de estas tierras. Uno de los problemas más graves era el de los precios. Antes eran fijados por las autoridades centrales y tenían poco que ver con los costos reales. Se trataba de que fuesen regulados por el mercado para utilizar los recursos racionalmente. Para que no descendieran mucho las inversiones en la industria pesada y no cayeran la producción y el empleo, hubo que buscar créditos internacionales, necesarios para comprar alta tecnología y lanzar la industria de consumo. Para conseguir créditos habría que hacer concesiones al exterior y permitir la salida de capitales en concepto de beneficios por inversiones extranjeras.

El grupo dirigente de la URSS liderado por Gorbachov estimaba que «la perestroika económica no tendría ninguna probabilidad de éxito sin una reforma profunda de los mecanismos políticos de la Unión Soviética» ${ }^{98}$. La democratización era "el motor principal de la perestroika, la principal garantía de su irreversibilidad" 99 . Se desmontó el monopolio del PCUS y se estableció una democracia con elecciones libres, división de poderes y alternancia en el poder, aunque con un desarrollo complicado y lleno de obstáculos.

El problema de Rusia es que las reformas económicas no han dado resultado. Los precios subieron, el desempleo creció y la deuda externa se disparó. Existe el riesgo de que se identifiquen las dificultades económicas con el precio que hay que pagar por la democracia. Sería necesaria una ayuda económica internacional más cuantiosa y sistemática 100

La evolución de los otros países de economía planificada de la Europa del Este ha sido muy similar. En algunos casos la reforma ha sido más radical y ha alcanzado mayor éxito económico y político. En este sentido, hay que destacar los logros de la República Checa, de Hungria y de Polonia. Estos tres países se han integrado ya en la OCDE y en la OTAN y son los mejor situados para integrarse en la Unión Europea en la primera ampliación de la misma.

En China, el proceso de grandes cambios comenzó en 1978. El crecimiento económico se obtendría mediante el incremento del comercio internacional, la apertura a las inversiones extranjeras, la importación de

98 Ramses 90, Informe Anual Mundial sobre el Sistema Económico y las Estrategias, dirs Thierry de Montbrial y Jacques Edin, Ed. Ciencias de la Dirección, 1990, p. 8.

99 A. AganBegyan, ob. cit., p. 289.

100 Véase J. K. Galbraith, La economia mundial: Presente y perspectivas de futuro, p. 9. 
tecnología, nuevos métodos de gestión y privatización de la agricultura. Se buscaba, además, el bienestar de la población a través del desarrollo de la industria de consumo, frente a la prioridad de la industria pesada de épocas anteriores.

Esta nueva política representaba el triunfo de la línea pragmática propugnada por Deng Xiaoping, frente a la línea radical que había representado Mao. Las reformas perseguían cinco objetivos: superar la ideología igualitarista de la era maoista, reestructurar la gestión de las industrias, reformar el sistema comercial ,potenciar el contacto con el exterior incentivando el desarrollo de "zonas económicas especiales" y revalorizar el papel de los intelectuales ${ }^{101}$.

La reforma fue más rápida en el campo que en las ciudades. A partir de 1978 se desencadenó el rápido desmantelamiento de las comunas, la descolectivización y el retorno a la tradicional unidad familiar agrícola. En 1979 se aprobó la ley sobre inversiones extranjeras. Los objetivos eran obtener capitales, e incorporar tecnología y nuevos métodos de gestión. La creación de «zonas económicas especiales» estaba destinada a atraer estas inversiones y experimentar las reformas, que, si prosperaban, se extenderian al resto de China. En cuanto a las empresas chinas sin participación extranjera, la reforma más importante consistió en la concesión de mayor autonomía y la sustitución de la planificación centralizada por un sistema en el que cada vez tuviera más peso el mercado.

Las reformas acercaron la economía china a la economía de mercado: maximizar los beneficios y lograr la mayor expansión posible. Se trataria de "demostrar el desarrollo de una economía de mercado en el marco de su perseverancia en el sistema socialista", mientras que hasta ahora la idea de mercado se había vinculado al capitalismo ${ }^{102}$.

Era imposible limitar las transformaciones al ámbito económico. En 1982 se revisó la constitución. Los artículos revisados establecian la igualdad de todos los ciudadanos ante la ley, la libertad de creencias religiosas, la inviolabilidad de domicilio y correspondencia, etc.. No obstante, la reforma nunca pretendió tocar sustancialmente el sistema político y menos aún al poder del Partido Comunista. La reforma se llevaría a cabo sin democracia. No existía intención de romper con el régimen, sino de institucionalizarlo. Así, cuando en 1978, en una atmósfera de liberalización, se empezaron a expresar con cierta libertad las ideas en carteles expuestos en

\footnotetext{
101 Enrique Fanjul, Reforma y crisis en China, Madrid, Arias Montano editores, 1991, p. 22.

102 Véase entrevista al presidente Jiang Zemin en El Pais, 27 junio 1996, p. 4.
} 
un muro, el movimiento liberalizador del «muro de la democracia» fue aplastado sin contemplaciones en marzo de 1979. Diez años más tarde, en junio de 1989, fue aplastado el movimiento de la plaza de Tiananmen, que demandaba la democratización del sistema. Los disidentes fueron perseguidos, encarcelados y ejecutados ${ }^{103}$.

Es posible que las disidencias ideológicas aumenten. La dictadura del partido se mantendrá con dificultades en una sociedad cada vez más diversificada, que permite el enriquecimiento. Con el desarrollo económico las presiones para una liberalización política se incrementarán y si fracasa la política económica y se estanca la economía pueden crecer esas presiones ${ }^{104}$.

11.2.7. Transiciones en América Latina. Expansión del sistema democrático

En América Latina, las clases dominantes han apelado, en muchos casos, a la democracia para desmovilizar a las clases populares; pero, igualmente, han recurrido a soluciones dictatoriales siempre que la democracia ya no era útil. A pesar de estos vaivenes, como consecuencia del fracaso económico y de la represión y violencia de las dictaduras, "la mayoría de las fuerzas políticas y culturales de algún peso atribuyen ahora un alto valor intrínseco al logro y consolidación de la democracia política» ${ }^{105}$. El clima ideológico ha cambiado sustancialmente; los intelectuales reclaman el pluralismo y la democratización política, mientras que hasta hace unos años, tanto los intelectuales de izquierdas como los de derechas eran hostiles a la democracia. Otro factor que impelía hacia la democracia era la profunda crisis económica a la que los regímenes autoritarios no sabian dar solución. Todo ello contribuyó al «desprestigio profundo y ampliamente difundido de la experiencia autoritaria (...), junto con el descrédito de los discursos y grupos que proponen un salto inmediato y violento hacia alguna forma de socialismo (...). En otras palabras, nunca el "prestigio" ideológico de la democracia política ha sido mayor que ahora en América Latina. Las ideas e instituciones autoritarias están desacreditadas» ${ }^{106 .}$

\footnotetext{
103 E. FANJUL, ob. cit. pp. 21, 43 y 46.

104 Z. BRZEZINSKI, El gran tracaso. Nacimiento y muerte del comunismo en el siglo $x x$, Madrid, Maeva, 1989, pp. 152-153

105 Guillermo O'DONNEL, «Introducción a los casos latinoamericanos" en G. O'DONNEL, P.C. SCHMITTER y L. WHITEHEAD (comp.), Transiciones desde un gobierno autoritario, vol. II, p. 32.

106 Ibidem, p. 35.
} 
Las presiones exteriores han jugado un papel importante en los procesos de democratización. La imposición de políticas económicas librecambistas ha repercutido en la liberalización política. El paso gradual a modelos internacionalistas de desarrollo ha incrementado la presión para que se adopten politicas "ortodoxas", que se ajusten al sistema capitalista mundial, y a ello están condicionados los créditos internacionales: libre mercado, medidas monetarias para controlar la inflación y mantener la regularidad cambiaria, política comercial que asegure movilidad de equipos, capitales y materias primas.

Los países en los que la subversión adquirió grandes proporciones ensayaron dictaduras militares, que se encargarían de ejecutar políticas neoliberales. En cuanto llegaron las dificultades económicas, la ausencia de base social y de acuerdo político hicieron peligrar el régimen. Los grupos dominantes retiraron su apoyo a los militares. Volvieron las protestas populares. Se establecieron sistemas democráticos, que se encargarian de poner en práctica esas mismas políticas pero con amplio consenso nacional.

En los países que arrastraban una larga dictadura (Brasil, Perú, etc.) y el peligro de subversión no era muy agudo, la crisis económica precipitó la crisis política. El empresariado empezó a demandar más libertad y menos intervencionismo. La crisis obligó a recortar el gasto público, los subsidios y las ayudas. Las instituciones financieras internacionales exigian políticas liberales para conceder sus créditos, necesarios para superar la crisis.

En todas partes la apertura política estaba influenciada por la crisis económica y por los dictados del Fondo Monetario Internacional. Entre 1988 y 1991 se celebraron elecciones libres en todos los estados latinoamericanos excepto en Cuba, hecho que no había ocurrido nunca en la historia. Esta situación se ha mantenido hasta la actualidad a pesar de los intentos frustrados de golpe de Estado en diversos paises, hecho que demuestra la fortaleza del sistema democrático en la década de los noventa. Y eso a pesar de los graves problemas económicos y sociales.

La democracia ha llegado también, recientemente, a países de otros continentes. Son llamativos los casos de Zimbawe y de la República Sudafricana, donde regía el cruel régimen del "apartheid". Angola y Mozambique, que habian tenido regímenes de inspiración soviética, han evolucionado, a partir de 1992, hacia sistemas más representativos. En Filipinas, el SE asiático, Oceanía, la democracia se extiende con dificultades. Según el anuario Freedom House, en 1972 habia 42 paises que se podían catalogar como democráticos, en 1980 su número aumentó a 52 y 
en 1992 alcanzó la cifra de $75^{107}$. Este fenómeno responde a un nuevo orden económico y político internacional, en el que la democracia cobra cada vez más prestigio entre el pueblo y los dirigentes, al tiempo que es la fórmula política que más apoyos internacionales recibe en la actualidad. 